\title{
Kaolinite particles as ice nuclei: learning from the use of different kaolinite samples and different coatings
}

\author{
H. Wex ${ }^{1}$, P. J. DeMott ${ }^{2}$, Y. Tobo ${ }^{2}$, S. Hartmann ${ }^{1}$, M. Rösch ${ }^{1}$, T. Clauss ${ }^{1}$, L. Tomsche ${ }^{1}$, D. Niedermeier ${ }^{1}$, and \\ F. Stratmann ${ }^{1}$ \\ ${ }^{1}$ Leibniz Institute for Tropospheric Research, Leipzig, Germany \\ ${ }^{2}$ Department of Atmospheric Science, Colorado State University, Fort Collins, Colorado, USA
}

Correspondence to: H. Wex (wex@tropos.de)

Received: 12 October 2013 - Published in Atmos. Chem. Phys. Discuss.: 21 November 2013

Revised: 3 April 2014 - Accepted: 19 April 2014 - Published: 4 June 2014

\begin{abstract}
Kaolinite particles from two different sources (Fluka and Clay Minerals Society (CMS)) were examined with respect to their ability to act as ice nuclei (IN). This was done in the water-subsaturated regime where often deposition ice nucleation is assumed to occur, and for watersupersaturated conditions, i.e., in the immersion freezing mode. Measurements were done using a flow tube (the Leipzig Aerosol Cloud Interaction Simulator, LACIS) and a continuous-flow diffusion chamber (CFDC). Pure and coated particles were used, with coating thicknesses of a few nanometers or less, where the coating consisted of levoglucosan, succinic acid or sulfuric acid. In general, it was found that the coatings strongly reduced deposition ice nucleation. Remaining ice formation in the water-subsaturated regime could be attributed to immersion freezing, with particles immersed in concentrated solutions formed by the coatings.

In the immersion freezing mode, ice nucleation rate coefficients $j_{\text {het }}$ from both instruments agreed well with each other, particularly when the residence times in the instruments were accounted for. Fluka kaolinite particles coated with either levoglucosan or succinic acid showed the same IN activity as pure Fluka kaolinite particles; i.e., it can be assumed that these two types of coating did not alter the ice-active surface chemically, and that the coatings were diluted enough in the droplets that were formed prior to the ice nucleation, so that freezing point depression was negligible. However, Fluka kaolinite particles, which were either coated with pure sulfuric acid or were first coated with the acid and then exposed to additional water vapor, both showed a reduced ability to nucleate ice compared to the pure particles. For the CMS kaolinite particles, the ability to nucleate ice
\end{abstract}

in the immersion freezing mode was similar for all examined particles, i.e., for the pure ones and the ones with the different types of coating. Moreover, $j_{\text {het }}$ derived for the CMS kaolinite particles was comparable to $j_{\text {het }}$ derived for Fluka kaolinite particles coated with sulfuric acid. This is suggestive for the Fluka kaolinite possessing a type of ice-nucleating surface feature which is not present on the CMS kaolinite, and which can be destroyed by reaction with sulfuric acid. This might be potassium feldspar.

\section{Introduction}

Ice in clouds is a research topic which received interest already before the 1950s (see e.g. Vonnegut, 1947). Despite many decades which have gone by since scientists started to work on ice in clouds, our understanding of even the basic related processes is still incomplete (Murray et al., 2012). In the atmosphere, ice-containing clouds (meaning both pure ice clouds and mixed-phase clouds) play important roles. They cover a significant fraction of the Earth at any time and hence influence radiative processes and also the formation of precipitation. Of the latter, the majority is produced via the ice phase in mixed-phase clouds, particularly outside of the tropics.

The first step on the way to having ice in clouds is ice formation, and therefore this process is of large interest. It is known that ice can form by primary or secondary processes, an example for the latter being rime splintering (Hallett and Mossop, 1974). The primary processes are either homogenous or heterogenous ice nucleation, where 
heterogeneous ice nucleation involves ice nuclei (IN) which lower the energy barrier that has to be overcome to form a stable ice cluster. Mixed-phase clouds form at temperatures above those for which homogenous ice nucleation can occur. And as these clouds are also the ones responsible for forming much of the globally occurring precipitation, the heterogenous ice nucleation mechanisms are of particular interest. Additionally, it has been claimed that, even for cirrus clouds, heterogenous formation mechanisms might be of large importance (Spichtinger and Cziczo, 2010; Cziczo et al., 2013).

There are different pathways for heterogenous freezing, generally discriminated into immersion, condensation and contact freezing and deposition ice nucleation. For mixedphase clouds, it has been stated that immersion freezing is the most important ice-forming mechanism (Ansmann et al., 2009; Wiacek et al., 2010; de Boer et al., 2011), while for cirrus clouds deposition ice nucleation and condensation freezing are additionally considered as ice-forming mechanisms. For the fourth heterogenous ice nucleation process, contact freezing, few data are available, but new results on this topic are currently emerging, e.g. in Hoffmann et al. (2013) and Ladino Moreno et al. (2013).

The difference between condensation and immersion freezing is poorly defined, and in the Appendix (Appendix A), a more detailed description of different definitions is given, based on Fukuta and Schaller (1982), Vali (1985), Pruppacher and Klett (1997) and Hoose and Möhler (2012). In our study, we will use the term immersion freezing for all cases when an insoluble particle is immersed in a diluted droplet. Condensation freezing will denote the case when an insoluble particle is immersed in a concentrated solution (i.e., in the case of haze particles), which principally can occur for $S_{\mathrm{w}}<1$ as long as the deliquescence relative humidity (DRH) of the soluble material which was on the insoluble core prior to forming a solution is overcome. This is similar to the "immersion freezing of solution droplets" from Hoose and Möhler (2012) or e.g. to a term called "deliquescent-heterogenous freezing" in Khvorostyanov and Curry (2004).

Much has been learned about the nature of IN (see the two reviews given by Hoose and Möhler, 2012 and Murray et al., 2012). However, on a process scale, it is still not known what exactly it is that makes a particle act as IN. Mineral dust particles are known to be an important IN source in the atmosphere (e.g. DeMott et al., 2003; Sassen et al., 2003; Cziczo et al., 2004; Hoose and Möhler, 2012; Murray et al., 2012; Atkinson et al., 2013). Particularly desert soils but also fertile soils of the Earth are abundant sources for mineral dust, and the respective aerosol is distributed worldwide, with a stronger abundance in the Northern Hemisphere (see e.g. Atkinson et al., 2013; Burrows et al., 2013). Different minerals have been examined with respect to their role as IN (see the summary in Murray et al., 2012), among them atmospherically relevant minerals like clay and feldspar and also quartz. Quartz was found to act as IN for deposition ice nucleation by Zimmermann et al. (2008) and for immer- sion freezing by Atkinson et al. (2013) but did not act as good IN for immersion freezing in measurements done with the Leipzig Aerosol Cloud Interaction Simulator (LACIS, unpublished results). There, quartz particles nucleated ice clearly less efficiently than particles from different kaolinite samples. In Zolles (2013), quartz samples bought from different companies were found to vary much in their ice nucleation ability for immersion freezing, showing median freezing temperatures between -24 and $-37^{\circ} \mathrm{C}$. Silicates generally are ice active (see e.g. Archuleta et al., 2005; Kanji et al., 2008; Zimmermann et al., 2008; Welti et al., 2009), and e.g. Sullivan et al. (2010a) and Niedermeier et al. (2011) explicitly mentioned that it might be the aluminosilicate minerals which are the most efficient ice-active component in the test dust examined in their studies (Arizona Test Dust, or ATD). Recently it has been proposed that the potassium feldspar content may play the most important role for the IN ability of mineral dusts worldwide (Atkinson et al., 2013).

A uniform description or parameterization which would enable an easy incorporation of the heterogenous freezing processes in models still needs to be developed, if this will be possible at all. Understanding the processes underlying the freezing and learning about the nature of IN can help shed light onto this. Particularly for the deposition ice nucleation, the review by Hoose and Möhler (2012) shows that reported onset temperatures scatter over a large range with respect to both observed temperature and water vapor saturation ratios. Some of this scatter can be explained by different thresholds, i.e., by different frozen fractions, which were reported for the different measurements that have been included in the comparison or by other issues specific to the different instruments. However, open issues remain for the understanding of heterogeneous ice nucleation. A new suggestion concerning deposition ice nucleation was recently discussed in Marcolli (2013), viewing this particular heterogenous ice nucleation mode as either homogeneous or as immersion freezing in pores and cavities. A part of this present study will be devoted to a related discussion. It has previously been described that coatings, particularly of sulfuric acid, on mineral dust particles containing aluminium silicates can largely reduce their ice nucleation ability for deposition ice nucleation (e.g. in Archuleta et al., 2005; Cziczo et al., 2009; Eastwood et al., 2009; Sullivan et al., 2010b; Tobo et al., 2012), and for immersion freezing (e.g. Zuberi et al., 2002; Koop and Zobrist, 2009; Niedermeier et al., 2010; Sullivan et al., 2010b; Niedermeier et al., 2011; Tobo et al., 2012). However, a coating of nitric acid inhibited deposition ice nucleation for relative humidities below $\sim 97 \%$ but not for immersion freezing (Sullivan et al., 2010a), and the observed sharp increase in ice nucleation ability at $\sim 97 \%$ was interpreted as a change in the heterogenous ice nucleation mode, namely from deposition ice nucleation to condensation/immersion freezing. In the present study, we will explicitly show that the ice nucleation for some coated mineral dust particles can be described as immersion freezing, with the mineral dust particle being 
immersed in a concentrated solution for which then a freezing point depression has to be assumed.

In the present work we will show results for heterogenous ice nucleation measured with either LACIS in its immersion freezing mode (Hartmann et al., 2011) and a CFDC (continuous-flow diffusion chamber; Rogers et al., 2001; DeMott et al., 2010) measuring both deposition ice nucleation and condensation/immersion freezing. Examined particles consisted of two different kaolinites with and without coatings (details are described in Sect. 2). In all cases, sizesegregated particles were examined.

A subset of the data presented here was already shown in Tobo et al. (2012), where data from the CFDC for Fluka kaolinite particles (pure and coated with $\mathrm{H}_{2} \mathrm{SO}_{4}$ or levoglucosan) were described. It was found that both coatings reduced the IN ability for the deposition ice nucleation while only the $\mathrm{H}_{2} \mathrm{SO}_{4}$ coating reduced the IN ability for condensation/immersion freezing in the CFDC. Therefore the levoglucosan coating was similar in its effect to nitric acid in Sullivan et al. (2010a) in inhibiting deposition ice nucleation but allowing for condensation/immersion freezing once the coating is dissolved at relative humidities close to $100 \%$.

The present study extends from Tobo et al. (2012). It includes a comparison of the measured immersion freezing by LACIS and the CFDC, additional data on CMS (Clay Minerals Society) kaolinite and also data on coatings with succinic acid. Furthermore, it discusses a model for describing the heterogeneous ice formation of particles with sufficiently thick coatings at relative humidities below $100 \%$, interpreting this type of freezing as immersion freezing of IN immersed in concentrated solutions.

\section{Samples, setup and instrumentation}

In this study, two different kaolinites were examined. The samples were provided by Fluka and by the CMS (KGa-1b). In general, kaolinite belongs to the group of clay minerals. It is a phyllosilicate (Deer et al., 1992) and occurs in atmospheric samples in amounts on the order of up to a few $10 \%$ (see Murray et al., 2012). However, the Fluka kaolinite additionally contains about $5 \%$ of potassium feldspar, while CMS kaolinite does not contain a detectable amount (Atkinson et al., 2013).

Besides pure particles, also coated particles were studied, where the coatings consisted of either sulfuric or succinic acid or levoglucosan. Sulfuric acid is known to be a reactive substance with the potential to decrease the IN ability of dust particles, as mentioned above. It is of atmospheric relevance as atmospheric $\mathrm{SO}_{2}$ can be oxidized to $\mathrm{H}_{2} \mathrm{SO}_{4}$ during wet-phase chemistry. Succinic acid was chosen as it is a slightly soluble substance with a high deliquescence relative humidity which is present in the atmosphere (Wex et al., 2007), while levoglucosan is an organic substance known to

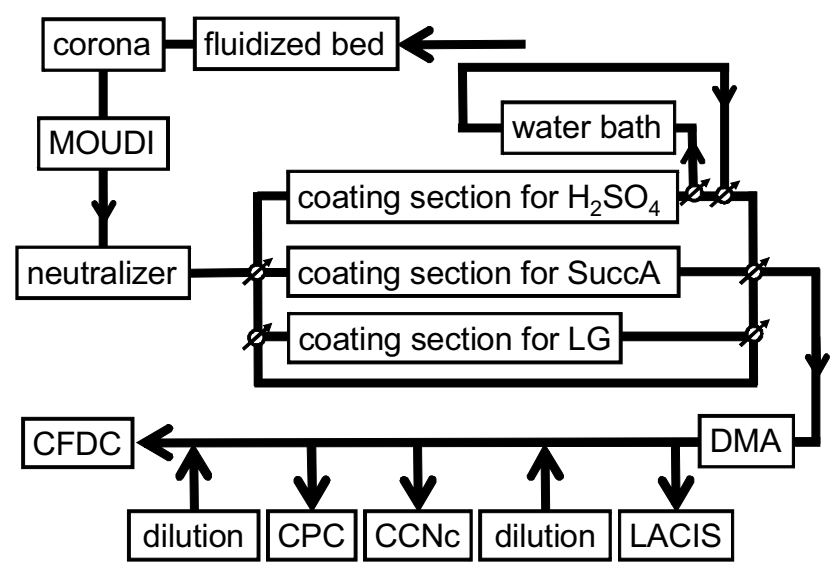

Figure 1. Setup of the particle generation.

be a tracer for biomass burning (Simoneit et al., 1999) with a much higher solubility.

A sketch of the general setup can be seen in Fig. 1. To disperse kaolinite particles, a fluidized bed generator (TSI 3400A, TSI Inc., St. Paul, Minnesota, USA) was used. In order to reduce the number of charges carried on the particles, and thereby to reduce the loss of charged particles to walls within the particle generation setup, a corona discharger was put in line behind the fluidized bed. The corona was produced on top of a needle to which high voltage $(4 \mathrm{kV})$ was applied. It has been tested previously that the corona discharger did not influence the IN ability of the particles (Niedermeier et al., 2010). We wanted to examine size-selected particles, and to facilitate the size selection a rough pre-selection was done; i.e., particles with aerodynamic diameters above 560 or $1000 \mathrm{~nm}$ (for the generation of 300 or $700 \mathrm{~nm}$ particles, respectively) were separated with a MOUDI impactor (Microorifice Uniform Deposition Impactor, Model 100R, MSP Corporation, Shoreview, Michigan, USA). Downstream of the MOUDI, a neutralizer established a bipolar equilibrium charge distribution on the particles.

When a coating was applied to the particles, the aerosol was then sent through one of three thermostated glass tubes, which contained either a reservoir filled with succinic acid $\left(\mathrm{C}_{4} \mathrm{H}_{6} \mathrm{O}_{4}\right.$, SuccA will be used as abbreviation for it from here on), levoglucosan $\left(\mathrm{C}_{6} \mathrm{H}_{10} \mathrm{O}_{5}\right.$, abbreviated $\left.\mathrm{LG}\right)$ or with sulfuric acid $\left(\mathrm{H}_{2} \mathrm{SO}_{4}\right)$. The temperature of the tubes was controlled via thermostats (HAAKE C25P, HAAKE GmbH, Karlsruhe, Germany). The glass tubes were set to temperatures between 45 and $90^{\circ} \mathrm{C}$, depending on the material and the desired coating thickness. For particles coated with $\mathrm{H}_{2} \mathrm{SO}_{4}$ at $70^{\circ} \mathrm{C}$, a further treatment was sometimes applied; i.e., water vapor was added to the aerosol by sending it over a water bath at room temperature and subsequently sending it through a second diffusion drier (not shown in the sketch). 
The coating section could also be bypassed, but, whether coated or not, particles were then sent through a DMA (differential mobility analyzer, type Vienna Hauke medium, aerosol-to-sheath air flow ratio of $1: 10$ ) to select particles with one mobility. Selected mobility diameters were either 300 or $700 \mathrm{~nm}$ throughout the experiments described herein. The aerosol was then distributed to the different instruments. In this part of the setup, two additional flows of particle-free air were added, where the particle number concentration was roughly halved in each of the steps. The different flows were controlled frequently, using a bubble flow meter, to enable the calculation of particle concentrations delivered to the different instruments. It was also ensured that a small excess of aerosol was produced. The small excess flow was vented in order to maintain the pressure in the whole particle generation setup close to laboratory pressure.

Directly downstream of the DMA, the aerosol was fed into LACIS, which was used to measure immersion freezing (Hartmann et al., 2011). LACIS consists of a $7 \mathrm{~m}$ long flow tube where each $1 \mathrm{~m}$ section can be temperature controlled separately. Temperatures can go down to $-50^{\circ} \mathrm{C}$. Before entering the flow tube, by use of a humidifier (PH-30T24KS, Perma Pure), the sheath air stream is hydrated such that droplets form on the aerosol particles upon cooling, i.e., during the passage of the flow tube. These droplets can subsequently freeze, depending on the nature of the immersed aerosol particle and the adjusted temperature. A detailed analysis of thermodynamic profiles in LACIS can be found in Hartmann et al. (2011). At the LACIS outlet, a self-built optical particle spectrometer (TOPS-Ice; Clauss et al., 2013) determines if the arriving hydrometeors are liquid droplets or frozen ice crystals, resulting in the determination of a frozen fraction, $f_{\text {ice }}$, i.e., the number of frozen droplets divided by the total number of liquid and frozen droplets.

Particle number concentrations were measured with a condensation particle counter (CPC, TSI 3010), which was operated in parallel to a cloud condensation nucleus counter (CCNc, Droplet Measurement Technologies) to determine the activation of the particles to cloud droplets and from that the coating thicknesses. Using both data from CPC and $\mathrm{CCNc}$, the fraction of all particles activated was determined. During the measurements, the supersaturation in the $\mathrm{CCNc}$ was scanned such that full activation curves, i.e., from none to all particles activated, were obtained.

Ice nucleation was also measured using a CFDC (Rogers et al., 2001; DeMott et al., 2010). The particle number concentrations delivered to this instrument were a few tens per cubic centimeter. The CFDC is operated with ice-covered walls which are kept at different temperatures. Temperatures can be set such that both sub- and supersaturation with respect to water vapor can be achieved for a focused aerosol lamina within the instrument. Evaporation of only liquid particles within the last section of the instrument facilitates optical detection of nucleated ice crystals. In this study, the IN number concentrations were determined as a function of wa- ter vapor saturation by stepwise scanning experimental conditions from ice saturation to a relative humidity (with respect to liquid water, $\mathrm{RH}_{\mathrm{w}}$ ) of about $107 \%$. It is assumed that although all ice formation mechanisms are possible in the regime above $100 \% \mathrm{RH}_{\mathrm{w}}$, this condition favors condensation/immersion freezing nucleation. Particularly close to $100 \% \mathrm{RH}_{\mathrm{w}}$, it might be possible that the particles are not activated to diluted droplets but form haze particles, instead, and the term condensation freezing should be understood correspondingly. To obtain frozen fractions, $f_{\text {ice }}$, from the CFDC measurements, measured total particle number concentrations were used together with the IN number concentrations; i.e., the same parameter was derived that was also obtained from the LACIS measurements.

\section{Results and discussion}

\subsection{Coating thicknesses}

We first discuss the amount of coatings present on the examined particles. Besides examining $300 \mathrm{~nm}$ particles from either Fluka or CMS kaolinite samples, also $700 \mathrm{~nm}$ Fluka kaolinite particles were used. Different coating temperatures were applied for all three coating substances - SuccA, LG and $\mathrm{H}_{2} \mathrm{SO}_{4}$ - where for the latter additionally water vapor was added in some cases. Particle generation was operated such that for the course of one experiment, which usually lasted around $2 \mathrm{~h}$, one type of particle with one type of coating was produced, while the different instruments examined the particles. The need for CFDC and LACIS to either reice or defrost, respectively, determined the length of an experiment. Some particle types were generated repeatedly for more than one of these 2-hourly time spans.

Scans of activated fractions vs. supersaturation were measured with the $\mathrm{CCNc}$ for all the different particle types. The critical supersaturations for droplet activation, i.e., the supersaturation at which $50 \%$ of all particles were activated, were derived applying an error function fit to the measured activated fraction curves.

The critical supersaturations for the pure particles were found to be 0.29 and $0.44 \%$ for the $300 \mathrm{~nm}$ Fluka and CMS kaolinite particles, respectively, and $0.17 \%$ for Fluka particles of $700 \mathrm{~nm}$. These critical supersaturations are lower than expected for purely insoluble particles. Still, when using $\kappa$ Köhler theory (Petters and Kreidenweis, 2007), these values correspond to $\kappa$ below 0.005 . A comparable or even larger $\kappa$ has been reported for different mineral dusts e.g. in Herich et al. (2009) and Koehler et al. (2009); i.e., mineral dust particles generally were observed to be more easily activated to a droplet than expected. Kumar et al. (2011) attributed this fact to adsorption of water on the insoluble component of the dust particle. However, Herich et al. (2009) and Koehler et al. (2009) both also found that $\kappa$ of the mineral dust particles increased when the particles had been sprayed from an aqueous 
solution (instead of dispersing them from a dry powder), and argued that this was due to a redistribution of small amounts of soluble material which had to have been present already on the dry particles. We follow that line of argument; i.e., we assume that a small amount of soluble impurities was present on the kaolinite particles examined in this study. Based on the observed critical supersaturations it can be estimated that this amounts to less than $1 \%$ of the mass of the examined particles.

Coated particles activated at lower supersaturations than the pure ones, due to the larger soluble mass available. This decrease in supersaturation between uncoated and coated particles was used to derive the amount of soluble material which had been added to the particle during coating. We assumed that the particles were spherical with an insoluble core and a mantle of soluble material of SuccA, LG or $\mathrm{H}_{2} \mathrm{SO}_{4}$ around them, depending on the coating. Derived coating thicknesses are given in Table 1. The corresponding $\kappa$ for the coated particles is $<0.02$ for thin and mediumthick coatings and to up to 0.05 for the thickest coatings. Coatings $<2 \mathrm{~nm}$ correspond to hygroscopic growth factors at $90 \%$ relative humidity below 1.1 , a value generally observed for the hydrophobic fraction of atmospheric aerosols. For a dryly dispersed Saharan mineral dust sample taken from a surface soil layer, Koehler et al. (2009) found a $\kappa$ of 0.054 . Herich et al. (2009) reported 0.02 and $<0.01$ for dryly dispersed mineral dust samples from the Sahara and the Takla Makan Desert, respectively. In general, coated particles used in our study, particularly those with thin and medium-thick coatings, are comparable in their hygroscopicity to naturally occurring mineral dust particles.

It should be mentioned that at least the $\mathrm{H}_{2} \mathrm{SO}_{4}$ coating most likely will have chemically reacted with the dust particles. Reitz et al. (2011) examined ATD particles coated with $\mathrm{H}_{2} \mathrm{SO}_{4}$, where the coating procedure was similar to the one in the present study, and it was reported that both sulfuric acid as well as sulfates were present on the particles. This suggests a reaction between the $\mathrm{H}_{2} \mathrm{SO}_{4}$ coating and the ATD. As the derived amount of coating depends on the hygroscopicity of the coating material, and as sulfates commonly have a lower hygroscopicity than sulfuric acid, coating thicknesses derived from our data could be up to a factor of 2 above those given in Table 1 for the $\mathrm{H}_{2} \mathrm{SO}_{4}$ coatings. Nevertheless, the derived coating thicknesses still can give a rough estimate and should only be viewed as such.

With sizes of the molecules of SuccA, LG and $\mathrm{H}_{2} \mathrm{SO}_{4}$ roughly in the range of $0.5 \mathrm{~nm}$, and with the shape of the particles likely being rather flaky than spherical, the coatings that were obtained for the lowest coating temperatures can be expected to not cover the whole particle surface, while the highest coating temperatures are much more likely to have produced a complete coating in all cases.

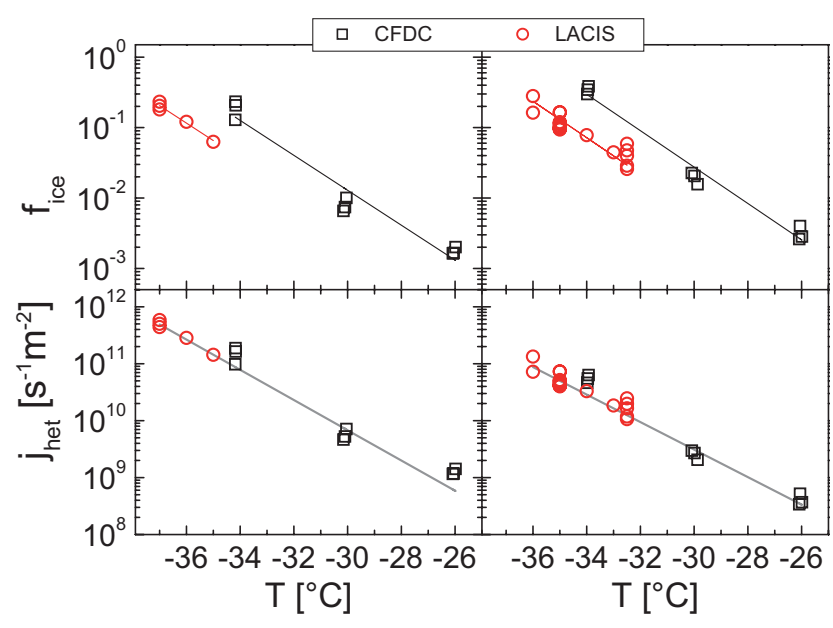

Figure 2. Measured $f_{\text {ice }}$ and derived $j_{\text {het }}$ for CFDC (at $104 \% \leq \mathrm{RH}_{\mathrm{W}} \leq 106 \%$ ) and LACIS (i.e., for immersion freezing) for two particle types. Left panels: $300 \mathrm{~nm}$ Fluka kaolinite coated with $\mathrm{LG}$ at $80^{\circ} \mathrm{C}$; right panels: $700 \mathrm{~nm}$ Fluka kaolinite (no coating).

\subsection{Immersion freezing}

Figure 2 shows exemplary freezing results from both CFDC and LACIS for two particle types. Shown are values for $f_{\text {ice, }}$, directly inferred from the measurements, and also for $j_{\text {het }}$, the heterogeneous freezing rate coefficient, calculated assuming pure stochastic freezing. The latter was obtained following e.g. Murray et al. (2012):

$f_{\text {ice }}=1-\exp \left(-j_{\text {het }} \cdot s \cdot t\right)$,

with the surface area of the examined particles $s$ and the freezing time $t$. While $t$ was $1.6 \mathrm{~s}$ for the LACIS measurements (see Hartmann et al., 2011), a residence time of $5 \mathrm{~s}$ was used for the CFDC, based on the maximum time for immersion freezing $\left(104-106 \% \mathrm{RH}_{\mathrm{W}}\right)$ in the CFDC, following the model of Rogers (1988) (see DeMott et al., 2014).

A stochastic approach for the description of immersion freezing induced by kaolinite has e.g. also been used in Murray et al. (2011), where a single type of active site was sufficient to describe the observed immersion freezing for a suite of different experimental conditions for a CMS kaolinite sample, pointing towards homogeneity of active sites on CMS kaolinite. For Fluka kaolinite, Pinti et al. (2012) reported two separate heterogeneous freezing peaks for measurements done with a differential scanning calorimeter. Wheeler and Bertram (2012) examined the onset of ice nucleation for deposition ice nucleation of Fluka kaolinite. They found that a model using a single contact angle did not reproduce their data well, while models using contact angle distributions as well as a simple deterministic model using a surface density of active sites were both able to describe their data. The latter results are consistent with Broadley et al. (2012), a study on immersion freezing of illite particles, which are considered as a more representative 
Table 1. Effective coating thicknesses, derived assuming spherical particles with a homogenous coating.

\begin{tabular}{|c|c|c|c|}
\hline Type of coating & $\begin{array}{l}\text { Fluka kaolinite, } 300 \mathrm{~nm} \\
\text { coating thickness }[\mathrm{nm}]\end{array}$ & $\begin{array}{l}\text { CMS kaolinite, } 300 \mathrm{~nm} \\
\text { coating thickness }[\mathrm{nm}]\end{array}$ & $\begin{array}{l}\text { Fluka kaolinite, } 700 \mathrm{~nm} \\
\text { coating thickness }[\mathrm{nm}]\end{array}$ \\
\hline \multicolumn{4}{|l|}{$\mathrm{H}_{2} \mathrm{SO}_{4}$} \\
\hline $45^{\circ} \mathrm{C}$ & 0.44 & & \\
\hline $70^{\circ} \mathrm{C}$ & $1.32^{\mathrm{b}}$ & $0.87^{\mathrm{a}}$ & $0.87^{\mathrm{b}}$ \\
\hline $70^{\circ} \mathrm{C}+\mathrm{H}_{2} \mathrm{O}$ & $1.77^{\mathrm{b}}$ & $1.48^{\mathrm{b}}$ & 1.57 \\
\hline \multicolumn{4}{|l|}{ LG } \\
\hline $60^{\circ} \mathrm{C}$ & 0.20 & & \\
\hline $80^{\circ} \mathrm{C}$ & $1.36^{\mathrm{a}}$ & & \\
\hline $93^{\circ} \mathrm{C}$ & $3.27^{\mathrm{a}}$ & $1.85^{\mathrm{b}}$ & $1.22^{\mathrm{a}}$ \\
\hline \multicolumn{4}{|l|}{ SuccA } \\
\hline $70^{\circ} \mathrm{C}$ & 0.11 & & \\
\hline $80^{\circ} \mathrm{C}$ & $0.54^{\mathrm{a}}$ & & \\
\hline $93^{\circ} \mathrm{C}$ & $4.78^{\mathrm{a}}$ & $3.17^{\mathrm{a}}$ & $1.58^{\mathrm{a}}$ \\
\hline
\end{tabular}

surrogate for atmospheric dusts. There, the use of a multicomponent stochastic model was required or, alternatively, the data could be approximated as freezing deterministically (without time dependence) for the purpose of atmospheric modeling. Therefore, while we mainly present and interpret our data based on a stochastic approach, in Appendix B the same data will be shown additionally when evaluated based on a deterministic approach.

Values for $f_{\text {ice }}$ given in Fig. 2 were fitted separately for the data from CFDC and from LACIS, and the curves are shown as black and red lines in the upper panels. An apparent shift in the data from CFDC to LACIS of up to $2 \mathrm{~K}$ could be interpreted from these curves. The fact that an analysis of $j_{\text {het }}$ brings the data into better alignment in the lower panel of Fig. 2 is consistent with the assumption of stochastic freezing for kaolinite particles, i.e., with the assumption that freezing is a time-dependent process, corroborating the results by Murray et al. (2011).

The two experiments shown in Fig. 2 are similar to what was found for all coated and uncoated kaolinite particles examined in this study. That is, analysis of $j_{\text {het }}$ always led to merger of data from CFDC and LACIS. Hence data from the two instruments were combined and fitted as one data set. This was done using

$j_{\text {het }}=A \cdot \exp (B \cdot T)$

where $T$ is the temperature (expressed in ${ }^{\circ} \mathrm{C}$ ), and $A$ and $B$ are the fitting parameters. Examples for the resulting fitting curves are included as grey lines in the two lower panels of Fig. 2. $A$ and $B$ were derived for all particle types for which data from both the CFDC and LACIS were available. All re- sulting fitting curves are displayed in Fig. 3, while resulting values for $A$ and $B$ are shown in Fig. 4

It has to be added that $A$ and $B$ were derived for the temperature range in which the measurements had been done (indicated by the grey shaded area in Fig. 3) and for residence times on the order of a few seconds. Hence the parameterizations underlying the curves shown for kaolinite IN in Fig. 3 are not necessarily valid outside the grey shaded area, nor for much longer timescales. It should also be added that the approach of parameterizing $j_{\text {het }}$ using the simple fit function given in Eq. (2) differs from calculation of nucleation rates based on classical nucleation theory (CNT) using a single contact angle. We parameterize $j_{\text {het }}$ and therefore describe its temperature dependence as obtained from the measurements. Using CNT together with a single contact angle tends to deliver temperature dependencies of nucleation rates which are too steep, unless all examined IN are identical. This can be seen e.g. in Augustin et al. (2013): a parameterization of nucleation rates similar to the one done in our study described measured frozen fractions almost as well as calculations based on CNT using a contact angle distribution, while calculations based on CNT with a single contact angle could not reproduce the measured data at all (compare Figs. 5 and A1 in Augustin et al., 2013).

The curves displayed in Fig. 3 roughly split into two groups, with the grey curve, i.e., the one for $300 \mathrm{~nm}$ Fluka kaolinite particles coated with the thinnest $\mathrm{H}_{2} \mathrm{SO}_{4}$ coating, applied at only $45^{\circ} \mathrm{C}$, belonging to neither. The first group of curves includes data for pure Fluka kaolinite and data for all Fluka kaolinite particles which were pure or coated with either SuccA or LG (corresponding to the top 10 curves given in the legend). Error bars depicting one standard deviation 


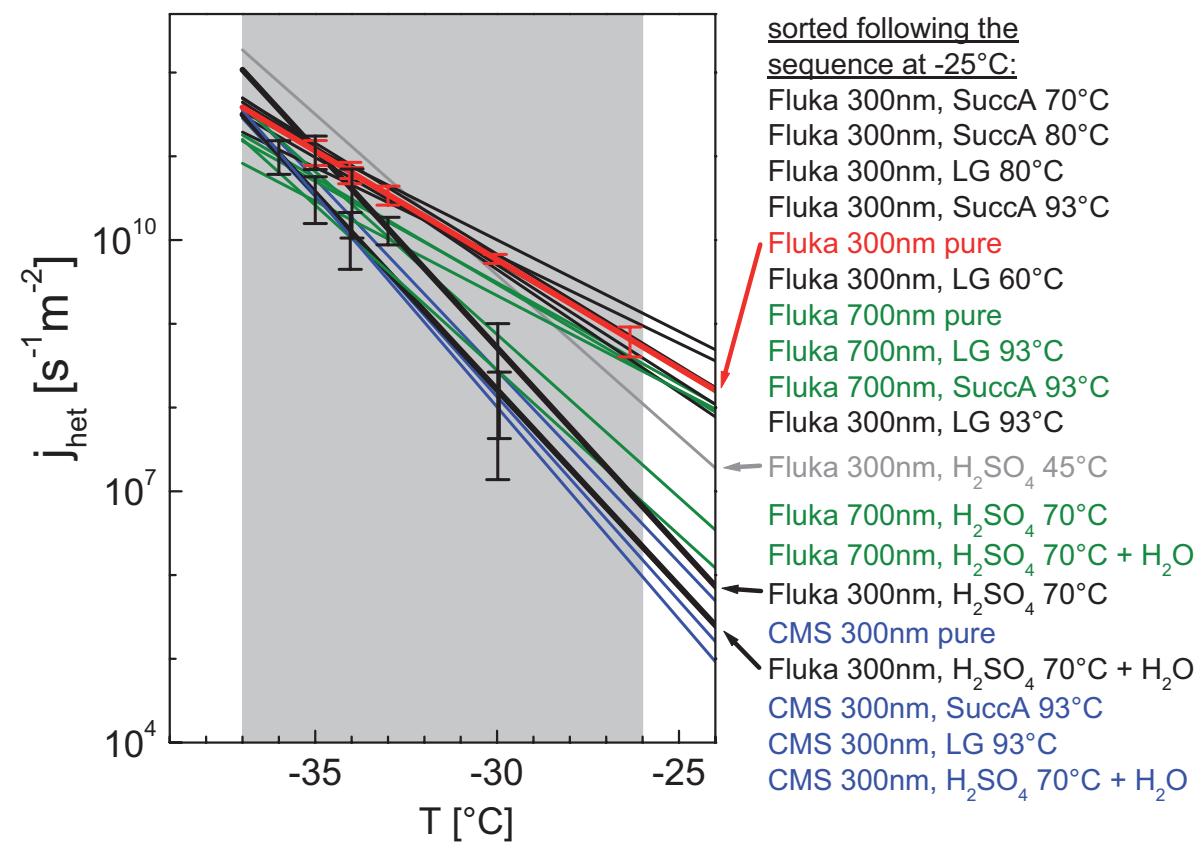

Figure 3. Fitting curves for $j_{\text {het }}$ for the different particle types, following Eq. (2). Corresponding values of the fit parameters $A$ and $B$ are shown in Fig. 4. $j_{\text {het }}$ for pure $300 \mathrm{~nm}$ Fluka kaolinite particles is shown in red, while black lines show $j_{\text {het }}$ for coated $300 \mathrm{~nm}$ Fluka kaolinite particles. A grey line indicates $300 \mathrm{~nm}$ Fluka kaolinite particles coated with $\mathrm{H}_{2} \mathrm{SO}_{4}$ at $45^{\circ} \mathrm{C}$ coating temperature. Pure and coated $700 \mathrm{~nm}$ Fluka kaolinite are shown in green, while blue lines depict $j_{\text {het }}$ for all CMS kaolinite particles. Error bars are given exemplarily for the red line and two black lines (for particle type see legend to the right of the plot).

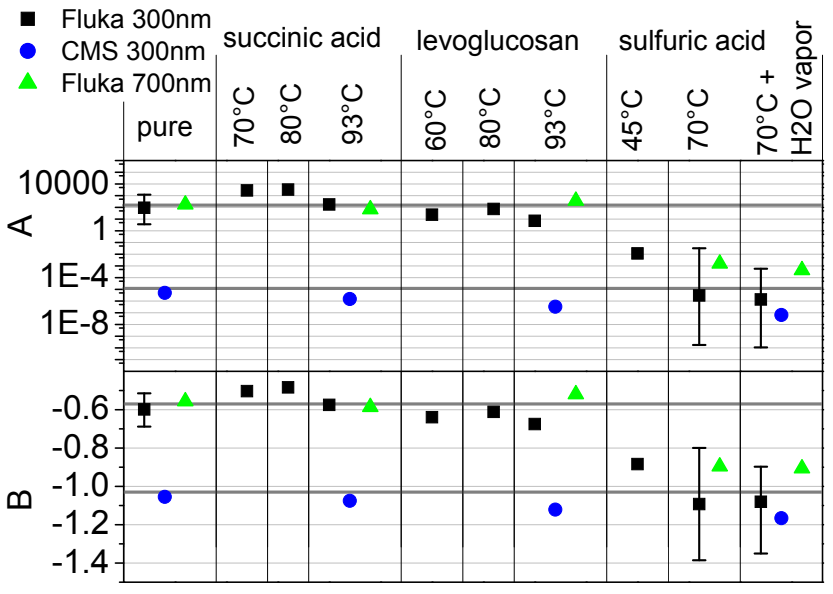

Figure 4. Overview over fit parameters $A$ and $B$ for $j_{\text {het }}$ for the different particle types. Error bars are given for the same data sets for which they were shown in Fig. 3. Grey horizontal lines give the average values for $A_{\text {Fluka }}, B_{\text {Fluka }}, A_{\mathrm{CMS}}$ and $B_{\mathrm{CMS}}$ as given in the text. were added exemplarily to the curve for the pure $300 \mathrm{~nm}$ Fluka kaolinite particles (shown in red). The second group contains all CMS kaolinite particles, regardless of the coating, and additionally also the Fluka kaolinite particles which had been coated with $\mathrm{H}_{2} \mathrm{SO}_{4}$ at $70{ }^{\circ} \mathrm{C}$ (with or without additional water vapor) (corresponding to the lowest eight curves given in the legend). Here, the two black curves in this group have error bars added to them, exemplarily. (It should be pointed out that the lowest black curve almost completely coincides with the next lower blue curve; hence only three different blue curves are clearly visible.) It can be seen that the CMS kaolinite particles and particles coated with $\mathrm{H}_{2} \mathrm{SO}_{4}$ are generally less ice active than particles belonging to the first group for temperatures above about $-34{ }^{\circ} \mathrm{C}$. Among all $300 \mathrm{~nm}$ Fluka kaolinite particles coated with $\mathrm{H}_{2} \mathrm{SO}_{4}$, those with the thinnest coating (grey curve) are clearly still the most ice active, indicating that the respective smaller amount of coating did not destroy the ice nucleation ability as thoroughly as did the thicker coatings.

We will now turn to Fig. 4, which resolves details better than Fig. 3. It can be seen that $A$ and $B$ show the same tendencies; i.e., when lower values were obtained for $A$, lower values were also obtained for $B$. When results were available for both 300 and $700 \mathrm{~nm}$ Fluka kaolinite, they were always similar, as is to be expected since the particle size is accounted for when deriving $j_{\text {het }}$. 
One of the most noticeable features in Fig. 4 is that the parameters obtained for the CMS kaolinite particles are clearly lower than those for the Fluka kaolinite for all particles except for those coated with $\mathrm{H}_{2} \mathrm{SO}_{4}$. This agrees with the literature available on immersion freezing of kaolinites, where generally CMS kaolinite was found to be less ice active than the Fluka kaolinite: Murray et al. (2011) used CMS kaolinite in their study and reported that they found a lower ice nucleation ability than Lüönd et al. (2010), a study in which Fluka kaolinite was used. Pinti et al. (2012) examined CMS kaolinite and kaolinite distributed by Sigma Aldrich (which is the same as that provided by Fluka) and found the Sigma Aldrich kaolinite to be more ice active. We will return to discussing the differences in the two types of kaolinite later in this section.

Coatings of SuccA or LG for all examined coating temperatures had no remarkable influence on the immersion freezing; i.e., $A$ and $B$ derived for the particles coated with SuccA or LG are similar to those for the respective uncoated particles. This holds true for Fluka and CMS kaolinite particles. This is not surprising, as SuccA and LG are both soluble substances, and for immersion freezing the droplets generated in the CFDC and in LACIS had maximum sizes above $2 \mu \mathrm{m}$ (Hartmann et al., 2011; DeMott et al., 2014); i.e., the soluble material on the particles was strongly diluted and freezing point depression is negligible. These results also suggest that SuccA and LG did not alter the surface of the particles chemically.

Concerning coatings of $\mathrm{H}_{2} \mathrm{SO}_{4}$, the data as shown in Fig. 4 reiterate and expand the point that this type of coating reduces the immersion freezing ability of Fluka kaolinite particles, visible in the lower $A$ and $B$ values. The addition of water vapor was intended to intensify the reaction between the acid and the kaolinite, as had been observed previously for ATD (Niedermeier et al., 2011), but this was not observed here.

Differently than for the Fluka kaolinite, a considerable decrease in the immersion freezing ability due to $\mathrm{H}_{2} \mathrm{SO}_{4}$ coating was not observed for the CMS kaolinite particles. A data set sufficient for evaluation exists only for the CMS kaolinite particles coated at $70^{\circ} \mathrm{C}$ with additional water vapor, which, however, should have been the most reactive coating produced.

The group of Fluka kaolinite particles of both sizes, either uncoated or coated with SuccA or LG, shows average values of $A_{\text {Fluka }}=155.4 \mathrm{~m}^{-2} \mathrm{~s}^{-1}$ and $B_{\text {Fluka }}=-0.57^{\circ} \mathrm{C}^{-1}$. The second group including all CMS kaolinite particles, regardless of the coating, and the Fluka kaolinite particles which had been coated with $\mathrm{H}_{2} \mathrm{SO}_{4}$ at $70^{\circ} \mathrm{C}$, with or without added water vapor have average values of $A_{\mathrm{CMS}}=1.21 \times$ $10^{-5} \mathrm{~m}^{-2} \mathrm{~s}^{-1}$ and $B_{\mathrm{CMS}}=-1.03^{\circ} \mathrm{C}^{-1}$.

The grouping of the data shows that although we used a strong acid we were not able to destroy ice nucleation sites on the CMS kaolinite much while we were able to do so on the Fluka kaolinite. It can be assumed that the $\mathrm{H}_{2} \mathrm{SO}_{4}$ coating causes a chemical reaction which alters the Fluka kaolinite, making the remaining particles similar in their IN ability to CMS kaolinite.

These results can be further interpreted when considering a recent publication by Atkinson et al. (2013). In that study, potassium feldspar is considered to be the most efficient ice-nucleating dusts under mixed-phase cloud conditions, globally. Atkinson et al. (2013) give the amount of potassium feldspar present in Fluka kaolinite to be roughly $5 \%$, while CMS kaolinite is reported to not contain any detectable amount. In general, common clay minerals are the weathering product of feldspar (Blum, 1994), and one transformation occurring in the field is the reaction of e.g. potassium feldspar with $\mathrm{H}^{+}$and $\mathrm{H}_{2} \mathrm{O}$ to form quartz and kaolinite. Therefore, the different fractions of feldspar in the two examined kaolinite samples hint towards the fact that the Fluka kaolinite is not weathered quite as thoroughly as the CMS kaolinite. The additional natural weathering likely is the reason for the reduced IN ability of the CMS kaolinite particles, and the feldspar contained in Fluka kaolinite might be responsible for the larger IN ability of this sample. In our experiments, it could be the altering of this feldspar when coating Fluka kaolinite with $\mathrm{H}_{2} \mathrm{SO}_{4}$ that causes the observed lowering in the IN ability.

The above-presented results on immersion freezing of the two different kaolinites are consistent with a corroboration of the claim by Atkinson et al. (2013), i.e., that it might indeed be the potassium feldspar which is responsible for an increased IN ability in some dusts.

\subsection{Ice nucleation under water-subsaturated conditions}

Now we will introduce measurements of ice nucleation in the regime below water saturation where deposition nucleation or freezing of haze particles may occur. These measurements were done only with the CFDC. Figure 5 shows $f_{\text {ice }}$ as determined with the CFDC for $300 \mathrm{~nm}$ Fluka, $300 \mathrm{~nm}$ CMS and $700 \mathrm{~nm}$ Fluka kaolinite particles for water-subsaturated conditions, for pure particles and those with medium-thick and thick coatings. Measurements for Fluka kaolinite were done at $-26,-30$ and $-34^{\circ} \mathrm{C}$, while the CMS kaolinite measurements were made at $-30,-34$ and $-38^{\circ} \mathrm{C}$. At the highest temperatures used for measurements for both kaolinites, ice was generally not detected. Compared to Fluka kaolinite particles, the CMS kaolinite particles were less active for ice nucleation in the water-subsaturated regime, similar to what was observed for immersion freezing of particles in dilute solutions above water saturation.

Results for $300 \mathrm{~nm}$ Fluka, $300 \mathrm{~nm}$ CMS and $700 \mathrm{~nm}$ Fluka kaolinite share some features in the observed ice nucleation in the water-subsaturated regime: (1) the uncoated kaolinite particles showed ice nucleation at a water vapor saturation ratio $\left(S_{\mathrm{w}}\right)$ below 0.95 clearly occurring at temperatures below $-34^{\circ} \mathrm{C}$ and even at $-30^{\circ} \mathrm{C}$ for the $700 \mathrm{~nm}$ Fluka kaolinite particles. (2) The coated particles examined here, which 
all had coating thicknesses above $0.5 \mathrm{~nm}$, lost the ability to induce apparent deposition ice nucleation at $S_{\mathrm{W}}$ below 0.95 . (3) These particles all started to induce ice at $S_{\mathrm{W}}$ above 0.95 , with a steep increase in the measured ice fractions towards saturation. The following paragraphs will show that for these particles with coating thicknesses above $0.5 \mathrm{~nm}$ deposition ice nucleation likely can not take place anymore, but that instead the measurements follow quantitatively what can be expected when immersion freezing in a concentrated solution takes place.

It is known that soluble material in a solution lowers the ice-melting temperature of that solution $\left(\Delta T_{\mathrm{m}}\right)$ compared to pure water, and that this lowering depends on the concentration, i.e., on the water activity $\left(a_{\mathrm{w}}\right)$, of the solution. This lowering is reflected in a lowering of the homogeneous freezing temperature $\left(\Delta T_{\text {hom }}\right)$. It was observed that there is a proportional relationship between $\Delta T_{\mathrm{hom}}$ and $\Delta T_{\mathrm{m}}$, yielding the socalled $\lambda$ approach: $\Delta T_{\text {hom }}=\lambda_{\text {hom }} \Delta T_{\mathrm{m}}$. This approach was first described by MacKenzie et al. (1977) and Rasmussen (1982) and was applied to model atmospheric homogenous freezing of droplets as early as in Sassen and Dodd (1988). Following Koop and Zobrist (2009) and the literature cited therein, $\lambda_{\text {hom }}$ can be expected to be on the order of 2 to 2.5 for the soluble substances we examined in our study.

The $\lambda$ approach can be extended to solutions with immersed IN, as suggested already in DeMott (2002) and applied e.g. in Zuberi et al. (2002), Archuleta et al. (2005) and Koop and Zobrist (2009) (where the latter gives an overview of publications on this topic, including both types of approaches, time-dependent and deterministic ones). The extended $\lambda$ approach results in a relationship between $\Delta T_{\mathrm{m}}$ and the freezing point depression for heterogeneous freezing $\left(\Delta T_{\text {het }}\right): \Delta T_{\text {het }}=\lambda_{\text {het }} \Delta T_{\mathrm{m}}$, where generally $1<\lambda_{\text {het }}<\lambda_{\text {hom }}$.

For our study, values for $\Delta T_{\mathrm{m}}$ vs. $a_{\mathrm{w}}$ were taken from Koop and Zobrist (2009). For the CFDC data, Köhler theory was used to convert $S_{\mathrm{w}}$ as adjusted during the measurements to $a_{\mathrm{w}}$. This was done based on particle hygroscopicities known from the CCNc measurements. With these, the Köhler equation was solved separately for each particle type and at the different values of $S_{\mathrm{w}}$ at which CFDC measurements had been done. This yielded the Kelvin term $(\mathrm{K})$ and the corresponding $a_{\mathrm{w}}$ (where $S_{\mathrm{W}}=\mathrm{K} \cdot a_{\mathrm{w}}$ ). As the examined dry particles were already at least 300 and $700 \mathrm{~nm}$ in diameter, the Kelvin term was below 1.006 and 1.003 , respectively, and the difference between $S_{\mathrm{w}}$ and $a_{\mathrm{w}}$ was correspondingly small.

For a coated kaolinite particle exposed to water vapor, the soluble material on the particle will dissolve as soon as $S_{\mathrm{W}}$ in the surroundings is above the deliquescence point of the soluble material, and (providing equilibrium is reached) a solution with $a_{\mathrm{W}}$ close to $S_{\mathrm{w}}$ will then be present on the particle surface. For $a_{\mathrm{w}}$ of e.g. 0.95 (where $\Delta T_{\mathrm{m}}=5.3$; Koop and Zobrist, 2009), the respective solution will cause a $\Delta T_{\text {het }}$ of 10.6 or $13.3 \mathrm{~K}$ for a $\lambda_{\text {het }}$ of 2 or 2.5 , respectively. Figure 6 illustrates what follows from this: the ice nucleation rates and likewise $j_{\text {het }}$ need to be shifted to lower temperatures. $j_{\text {het }}$ can

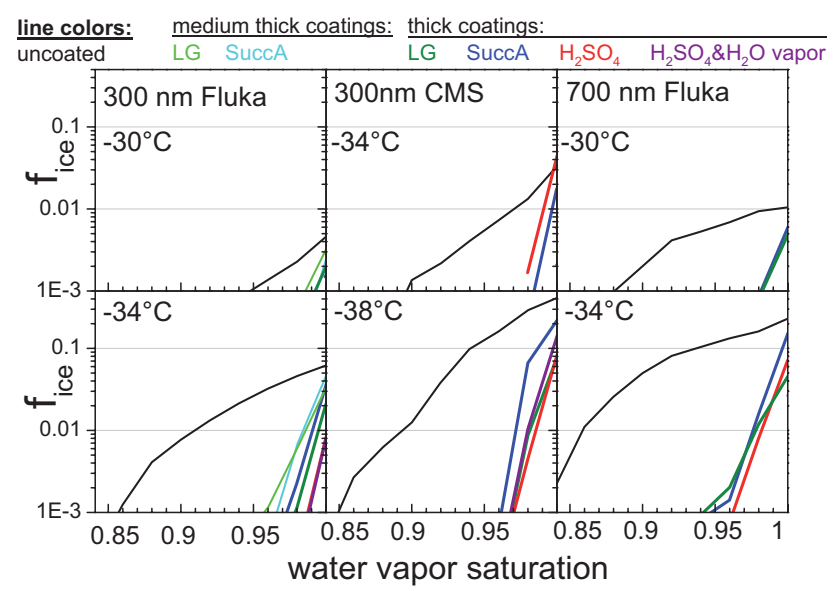

Figure 5. $f_{\text {ice }}$ measured with the CFDC for $S_{\mathrm{W}}<1$. Thinner lines indicate medium-thick coatings; thicker lines represent thick coatings. The type of coating is indicated by color; the color coding can be seen above the panels. Some lines cover others, and therefore it is additionally indicated in Table 1, for which of the particle types deposition ice nucleation was detected and is hence shown here.

be calculated based on Eq. (2), using the values of $A$ and $B$ as given in Fig. 4 and assuming that the ice nucleation takes place at a temperature which is increased by $\Delta T_{\text {het }}$ compared to the temperature of the surrounding. This causes $j_{\text {het }}$ to be shifted in the direction of the arrow in Fig. 6. The black curve shows $j_{\text {het }}$ for uncoated $300 \mathrm{~nm}$ Fluka kaolinite particles, based on the respective $A$ and $B$ given in Fig. 4 . The curves in different shades of grey show this same curve for such particles immersed in solutions with $0.99 \leq a_{\mathrm{w}} \leq 0.94$ for a $\lambda_{\text {het }}$ of 2 . The black vertical line indicates which values for $j_{\text {het }}$ would be expected at $-34{ }^{\circ} \mathrm{C}$ for differently concentrated solutions, showing that e.g. at an $a_{\mathrm{w}}$ of $0.95, j_{\text {het }}$ is reduced by roughly 3 orders of magnitude.

For our further analysis, a combination of Eqs. (1) and (2), including the freezing point depression, was used:

$f_{\text {ice }}\left(a_{\mathrm{w}}\right)=1-\exp \left(-A \cdot \exp \left(B \cdot\left(T+\Delta T_{\text {het }}\left(a_{\mathrm{w}}\right)\right)\right) s \cdot t\right)$.

The average values $A_{\text {Fluka }}$ and $B_{\text {Fluka }}$ were used, together with the residence time in the CFDC of $5 \mathrm{~s}$, to calculate $f_{\text {ice }}$ at $-34{ }^{\circ} \mathrm{C}$ for the 300 and $700 \mathrm{~nm}$ Fluka kaolinite particles, as a function of water activity. Results are shown in Fig. 7 as grey shaded areas (panels a and b). These areas cover results for $\lambda_{\text {het }}$ between 1 (left edge) and 2.5 (right edge), and a grey line in their middle represents $\lambda_{\text {het }}=1.7$. $\lambda_{\text {het }}$ of 1 and 2.5 are a conservative lower and upper bound, where for $\lambda_{\text {het }}=1$ it would be $\Delta T_{\text {het }}=\Delta T_{\text {hom }}=\Delta T_{\mathrm{m}}$, and therefore this bound can be expected to underestimate the freezing point depression and likewise the suppression of freezing. A $\lambda_{\text {het }}$ of 1.7 was chosen as this value was found in Zuberi et al. (2002) to fit their data for freezing of kaolinite and montmorillonite particles in aqueous solutions containing $\left(\mathrm{NH}_{4}\right)_{2} \mathrm{SO}_{4}$. Also shown in Fig. 7 in panels a and b is $f_{\text {ice }}$ measured with the 


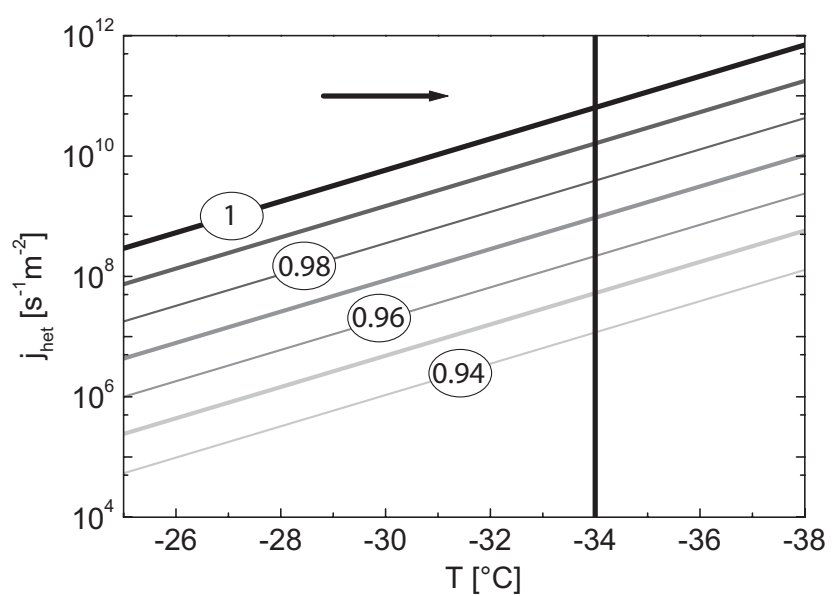

Figure 6. $j_{\text {het }}$ estimated for different water activities $a_{\mathrm{w}}$ in a solution droplet surrounding a particle. The black line labeled " 1 " is the one for the uncoated $300 \mathrm{~nm}$ Fluka kaolinite particles. The different grey lines indicate the curves for $j_{\text {het }}$ for such particles immersed in a solution with $0.94 \leq a_{\mathrm{w}} \leq 0.99$ (values for $a_{\mathrm{w}}$ indicated on every other line). The vertical black line at $-34^{\circ} \mathrm{C}$ was drawn as a guide for the eye, to indicate how much $j_{\text {het }}$ changes for different $a_{\mathrm{w}}$ at a fixed temperature (i.e., when measurements were done at a fixed temperature but for differently concentrated solutions).

CFDC for medium and thickly coated particles with SuccA or LG coating.

The grey shaded areas now represent the range where freezing induced by the pure particles can be expected when they are immersed in a solution. And indeed, both the observed temperature range and slope of the measured freezing behavior for the Fluka kaolinite particles coated with SuccA and LG are well captured. It should be noted here that the CFDC has an uncertainty in relative humidity of roughly $3 \%$, i.e., about 0.03 in water activity, so that measured and calculated values all agree within uncertainty.

It has to be noted here explicitly that the parameters $A_{\text {Fluka }}$ and $B_{\text {Fluka }}$ determined from the immersion freezing are valid for the Fluka kaolinite in our experiments as long as it is not coated with $\mathrm{H}_{2} \mathrm{SO}_{4}$, i.e., as long as it is not altered. Applying the above-described model to Fluka kaolinite coated with $\mathrm{H}_{2} \mathrm{SO}_{4}$ or to CMS kaolinite requires use of the average values of $A_{\mathrm{CMS}}$ and $B_{\mathrm{CMS}}$. When this is done, the red striped areas in Fig. 7 (panels c to e) are obtained. Again, a grey line represents results for $\lambda_{\text {het }}=1.7$. For the Fluka kaolinite particles, the location of the red striped areas, compared to the grey areas, reflect the fact that these particles showed a reduced immersion freezing ability upon coating with $\mathrm{H}_{2} \mathrm{SO}_{4}$; hence they are shifted to lower $f_{\text {ice }}$ (or seemingly larger water activities).

When comparing the measured values for the two different groups of IN, indeed, the $300 \mathrm{~nm}$ Fluka kaolinite particles coated with either SuccA or LG show an increased freezing ability compared to these particles coated with $\mathrm{H}_{2} \mathrm{SO}_{4}$ (with

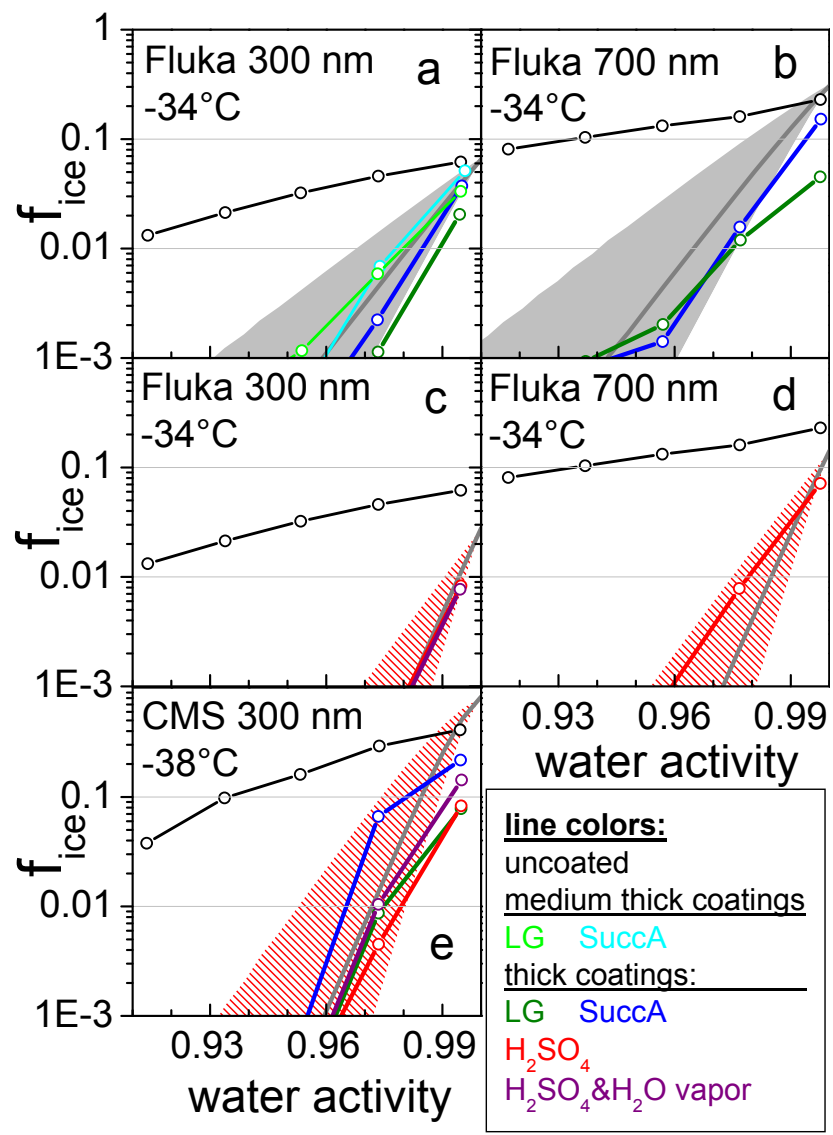

Figure 7. Measured $f_{\text {ice }}$ for deposition ice nucleation and expected ice nucleation behavior for particles which are completely coated by a solution (grey areas for Fluka kaolinite coated with SuccA or LG, and red striped areas for CMS kaolinite and Fluka kaolinite coated with $\mathrm{H}_{2} \mathrm{SO}_{4}$ ). The color code for the measured data with respect to the type of coating is similar to that used in Fig. 5.

or without additional water vapor). Such a clear difference in $f_{\text {ice }}$ between SuccA and LG coating to the two coatings with $\mathrm{H}_{2} \mathrm{SO}_{4}$ is not seen for the $300 \mathrm{~nm}$ CMS kaolinite particles, where it would not have been expected. All in all, when considering the above-mentioned measurement uncertainty of the CFDC and including all particles and coatings, measured and calculated values are well in agreement within uncertainty in the examined $\lambda_{\text {het }}$ range and even with $\lambda_{\text {het }}$ of 1.7. Unfortunately, the measurement uncertainties do not allow for a more constrained determination of $\lambda_{\text {het }}$.

Our results support that particles with medium-thick and thick coatings examined in our study did not show deposition ice nucleation behavior anymore, in the whole range of $S_{\mathrm{w}}<1$. At relative humidities below the deliquescence point of the coating material, ice nucleation sites were covered and freezing was inhibited. Above the deliquescence relative humidity, additional water was added to the coating and a solution shell formed around the particles, causing them to rather nucleate ice from concentrated solutions via the immersion 


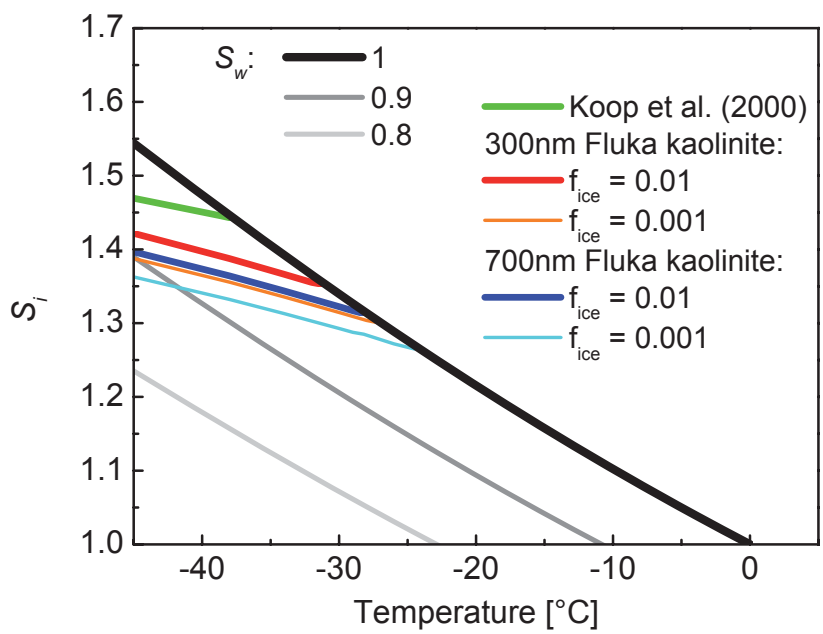

Figure 8. The plot shows the relation between the water vapor saturation ratio above ice $\left(S_{\mathrm{i}}\right)$ to that above water $S_{\mathrm{W}}$. Lines are shown for $S_{\mathrm{W}}$ of $0.8,0.9$ and 1 . Also shown is a line for homogeneous freezing taken from Koop et al. (2000) and lines indicating an $f_{\text {ice }}$ of 1 and $0.1 \%$ for the 300 and $700 \mathrm{~nm}$ particles with SuccA or LG coating examined in this study, calculated using Eq. (3).

freezing pathway. The solutions were so concentrated that immersion freezing was quenched due to freezing point depression. This is well in line with observations reported in Archuleta et al. (2005), Eastwood et al. (2009) and Sullivan et al. (2010a), where it was concluded for the heterogenous freezing of coated particles in the water vapor subsaturated range that freezing could only be initiated once the coating was dissolved.

An open issue is why also SuccA, a slightly soluble substance, seems to form a solution at water activities below 0.99 , where it should not dissolve. DRH of SuccA is $0.99 \%$ at room temperature (Wex et al., 2007) and can be expected to be similar or even larger in our experiments due to a decrease of solubility of SuccA with temperature (Parsons et al., 2004). However, as stated above, likely the applied coatings were not the only soluble materials on the particle surfaces. Mixtures tend to deliquesce at lower $S_{\mathrm{w}}$ than the pure substances (Marcolli et al., 2004), and the coexistence of the coating material with impurities on the kaolinite surfaces might be an explanation for the observations. Another explanation would be that during the coating SuccA did not condense in its crystalline form, but in a glassy state. In this case, deliquescence of the coating might have occurred at a lower DRH than if the SuccA had been crystalline (Mikhailov et al., 2009).

Figure 8 shows the relation of $S_{\mathrm{w}}$ to the water vapor saturation ratio above ice $\left(S_{\mathrm{i}}\right)$ as a function of temperature, in a way which is typical for displaying results particularly for deposition ice nucleation. A black, grey and light grey line correspond to $S_{\mathrm{w}}$ of $1,0.9$ and 0.8 , respectively. For reference, a green line is shown for homogeneous freezing of solution droplets taken from Koop et al. (2000). Furthermore, lines are inserted which are based on the above-presented parameterization (Eq. 3) for 300 and $700 \mathrm{~nm}$ Fluka kaolinite particles with SuccA or LG coatings, assuming a $\lambda_{\text {het }}$ of 1.7. The lines correspond to a frozen fraction $\left(f_{\text {ice }}\right)$ of 0.1 and $1 \%$. These lines and the one for $S_{\mathrm{w}}=1$ limit the range in which the above-described effect, i.e., immersion freezing of concentrated solution droplets, can occur in our study. This range will become larger for larger nucleation rates $\left(j_{\text {het }} \cdot s\right)$, i.e., either for larger particles (as can be seen e.g. by comparing the data for 300 and $700 \mathrm{~nm}$ in Fig. 8) or for more ice-active IN (e.g biological IN; see Murray et al., 2012). Deposition ice nucleation can still occur within this range when a potential IN is not completely coated. However, in the literature the range of freezing onsets (temperature and $S_{\mathrm{w}}$ ) reported for deposition ice nucleation is very large for any one IN particle type (Hoose and Möhler, 2012), and besides instrumental and experimental issues, some of this scatter might be explained by wrongly attributing immersion freezing in concentrated solutions to deposition ice nucleation instead.

The above-described results support the hypothesis that condensation and immersion freezing (i.e., the ice nucleation of an insoluble core immersed in a haze particle or in a diluted droplet) might basically be the same process, with the only distinction that a freezing point depression has to be accounted for in the subsaturated regime (i.e., for the haze particles). Eq. (3) (and likely also other temperature dependent parameterizations; see e.g. Appendix B) could be used to describe the freezing of droplets consisting either of concentrated or of dilute solutions with an immersed ice nucleus, where care only has to be taken to include the freezing point depression for the concentrated solutions correctly, whereas $\Delta T_{\text {het }}=0$ for diluted solutions. In e.g. Khvorostyanov and Curry (2004) it is argued that atmospheric IN are not necessarily insoluble but that rather a significant fraction is mixed with soluble material, motivating the development of a model describing "deliquescent-heterogenous freezing" following a concept comparable to the one we used here. Recently, Knopf and Alpert (2013) developed a model for describing immersion freezing of water and aqueous-solution droplets, depending on the suspended IN types and $a_{\mathrm{w}}$, in which kinetic effects were accounted for. Except for the latter, this is comparable to an approach given in Koop and Zobrist (2009), and it is very similar to the approach described in the present study, which is discussed in more detail in Appendix C. It is hence not a new idea when we argue that condensation and immersion freezing are similar, but by including a comparison of measured and modeled data for both the sub- and supersaturated regime, we corroborated this assumption. Future work should aim at testing our hypothesis, potentially making a discrimination between the two modes, condensation and immersion freezing, unnecessary. 


\section{Summary and conclusions}

In the present study, we examined immersion freezing and ice nucleation in the water-subsaturated regime for sizesegregated particles from two types of kaolinite, provided by Fluka and CMS. Pure particles were examined, and also particles with coatings of below up to a few nanometers of $\mathrm{H}_{2} \mathrm{SO}_{4}$, SuccA and LG. Freezing measurements were done using two different instruments, LACIS (Hartmann et al., 2011) and a CFDC (DeMott et al., 2010), where both instruments measured in the water-supersaturated regime, while deposition ice nucleation or other mechanisms possible in the water-subsaturated regime were only examined by the CFDC.

Frozen fractions observed by the two instruments in the immersion freezing regime differed, being seemingly apart by up to $2 \mathrm{~K}$. However, when considering a time dependence of the freezing process based on a stochastic approach, i.e., when comparing nucleation rate coefficients, these differences were diminished; i.e., the data observed by LACIS and the CFDC were in good agreement. However, as we used a simple formulation for describing the time dependence of the nucleation rate coefficients, our approach may not be generally valid for all types of IN. For example, in Broadley et al. (2012) heterogenous freezing induced by illite particles could only be characterized by either a multicomponent stochastic model or a deterministic model. Also, DeMott et al. (2014) discuss other instrumental factors for the CFDC that require clarification before all caveats may be removed in interpreting data from this instrument stochastically. Therefore, data analysis in this study was also done using a deterministic approach, and it was found that both the time-dependent and the deterministic approach yielded similar results.

Our results concerning the IN ability of the pure minerals corroborate earlier findings; i.e., CMS kaolinite generally was found to be less ice active than Fluka kaolinite in both immersion freezing and in deposition ice nucleation, and deposition ice nucleation generally was found to be the less effective heterogenous freezing process, compared to immersion freezing.

In the case of immersion freezing, the organic coatings used in our study did not reduce the IN ability of either kaolinite; i.e., these coatings did not alter the surface of the particles irreversibly and formed a very dilute solution when the particles were activated to droplets prior to freezing. On the other hand, $\mathrm{H}_{2} \mathrm{SO}_{4}$ coatings did reduce the IN ability of the Fluka kaolinite remarkably, but left the IN ability of the CMS kaolinite almost unchanged. This observation could potentially be explained by attributing the higher IN ability of the Fluka kaolinite to its content of potassium feldspar, a mineral which is not present in the CMS kaolinite and which likely is destroyed on contact with $\mathrm{H}_{2} \mathrm{SO}_{4}$. This hypothesis aligns with a recent publication by Atkinson et al. (2013), where potassium feldspar was found to be the most important mineral dust for atmospheric ice nucleation.

Ice nucleation at below water saturation was found to be impeded by all coatings with coating thicknesses above $0.5 \mathrm{~nm}$ for $S_{\mathrm{w}}$ below about 0.95 , while at $S_{\mathrm{w}} \geq 0.95$ a steep increase in the observed freezing was seen. Consistent with previous hypotheses, we showed that these observations can be explained by assuming that deposition ice nucleation likely does not take place anymore for the examined particles, but that instead the measurements follow what can be expected when immersion freezing in a concentrated solution takes place. The coatings examined in this case correspond to a hygroscopicity parameter $\kappa$ of the overall dust particle of about 0.05 , showing that the amount of soluble material present on a particle which suffices to hinder deposition ice nucleation is small. This might explain some of the observed scatter in the data for deposition ice nucleation reported in the literature in the past; i.e., some of the observation might not have been deposition ice nucleation but immersion freezing in a concentrated solution, instead. This also points towards the possibility that deposition ice nucleation might play an even smaller role in atmospheric processes than so far expected.

The fact that the parameterization we derived for the immersion freezing regime could also be used to model the freezing behavior of the IN immersed in concentrated solution droplets indicates that maybe all freezing processes which include a (more or less concentrated) solution shell which formed around an IN prior to freezing might be treated as being the very same process. The term immersion freezing has generally been used for all cases when an insoluble particle is immersed in a diluted droplet, and e.g. Koop and Zobrist (2009) and Hoose and Möhler (2012) additionally used it for immersion freezing in (more concentrated) aqueous solutions. Although the definition of condensation freezing has previously been less well defined, we argue that this should include all cases when an insoluble particle is immersed in a concentrated solution (i.e., in the case of haze particles), which principally can occur for $S_{\mathrm{w}}<1$ as long as the deliquescence RH of the soluble material which was on the insoluble core prior to forming a solution is overcome. We show in the present study that these two heterogenous freezing modes, i.e., condensation and immersion freezing, can be treated similarly, only by accounting for a freezing point depression for the haze particles. This potentially reduces the number of heterogenous freezing processes which need to be considered separately in atmospheric models to three, namely deposition ice nucleation, contact freezing and the here-examined condensation/immersion freezing. This is in line with what was already said by Fukuta and Schaller (1982), i.e., that there are three main mechanisms of heterogenous ice nucleation. 


\section{Appendix A}

Fukuta and Schaller (1982) wrote that there "are presently three main mechanisms of heterogeneous ice nucleation known by aerosol particles - deposition, condensationfreezing including immersion freezing, and contactfreezing". Nevertheless they try to distinguish between condensation and immersion freezing as follows: "In the process of condensation-freezing nucleation, liquid water forms on the ice nucleus surface before freezing nucleation takes place in it. If the liquid has existed for some time on the nucleus surface before the freezing nucleation starts, the process is considered as immersion-freezing." Vali (1985) listed four different heterogenous ice nucleation mechanisms and distinguished between condensation and immersion freezing, defining immersion freezing as "nucleation of supercooled water by a nucleus suspended in the body of water", where the "body of water" is not defined more precisely and could hence include both diluted droplets as well as haze particles (with haze particles being particles with at least some soluble material on them, which are in an environment where the RH is above the deliquescence $\mathrm{RH}$ of the soluble material but below the value needed for activation to a cloud droplet; see also Vali, 1985). Also following Vali (1985), condensation freezing occurs when "a cloud condensation nucleus (CCN) initiates freezing of the condensate". However, no further refinement of the definition is given, e.g., with respect to the amount of the condensate. It should also be pointed out here that this definition overlaps with the one for immersion freezing as cloud droplet activation is one way of getting a nucleus suspended in water. Following Pruppacher and Klett (1997) (p. 309 in the second edition), where also four distinct modes are described for heterogeneous ice nucleation, condensation freezing denotes the process during which an IN is activated to a droplet below $0^{\circ} \mathrm{C}$ and subsequently freezes (it is not clarified if this happens with or without further cooling), while during the immersion freezing process the IN enters the droplet above $0^{\circ} \mathrm{C}$ and the droplet then freezes once it is cooled sufficiently. A schematic in Fig. 1 in Hoose and Möhler (2012) suggests that immersion freezing represents a process by which a droplet with an immersed IN freezes upon further cooling (seemingly independent from the temperature at which the droplet formed). Condensation freezing in this schematic is indicated as a process during which condensation of water onto the IN occurs at water vapor saturation, leading to ice nucleation possibly upon further cooling. A separate process is indicated in this schematic as "immersion freezing of solution droplets" (i.e., haze particles).

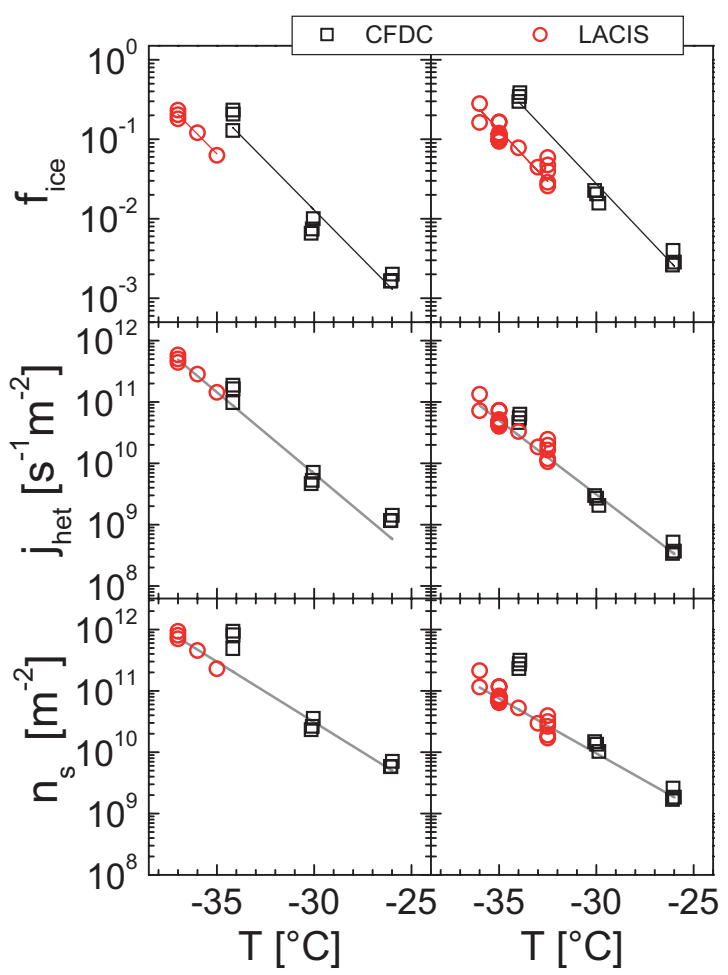

Figure B1. Measured $f_{\text {ice }}$ and derived $j_{\text {het }}$ for CFDC (at $104 \% \leq \mathrm{RH}_{\mathrm{W}} \leq 106 \%$ ) and LACIS (i.e., for immersion freezing) for two particle types. Left panels: $300 \mathrm{~nm}$ Fluka kaolinite coated with $\mathrm{LG}$ at $80^{\circ} \mathrm{C}$; right panels: $700 \mathrm{~nm}$ Fluka kaolinite (no coating).

\section{Appendix B}

Data in this study have been evaluated and interpreted based on Eq. (1), i.e., using an stochastic approach. Here, now, it is shown how it influences the results of our study when a deterministic approach (surface site densities $n_{\mathrm{S}}$ ) is used instead:

$f_{\text {ice }}=1-\exp \left(-n_{\mathrm{s}} \cdot s\right)$.

Figure B1 is a reproduction of Fig. 2, additionally showing data for $n_{\mathrm{s}}$ in the two lowest panels, obtained using Eq. (B1). As before, for each of the 19 different particle types CFDC and LACIS data were always combined to one data set, and fitted using $n_{\mathrm{S}}=A^{\prime} \cdot \exp \left(B^{\prime} \cdot T\right)$. The corresponding fit is shown as a grey line in the two lower panels of Fig. B1. For the two particle types shown in Fig. B1 and also for all others, the slope of $n_{\mathrm{s}}$ versus temperature is slightly less steep than that of $j_{\text {het }}$.

$A^{\prime}$ and $B^{\prime}$ for all 19 different particle types are shown in Fig. B2. This figure is comparable to Fig. 4, only now the fit parameters describe $n_{\mathrm{s}}$ instead of $j_{\text {het }}$. Grouping of the data is similar to that observed for $j_{\text {het }}$. Similar values of $A^{\prime}$ and $B^{\prime}$ are obtained for all Fluka kaolinite particles which were either uncoated or coated with SuccA or LG. A second set of $A^{\prime}$ and $B^{\prime}$ values which are similar to each other but 


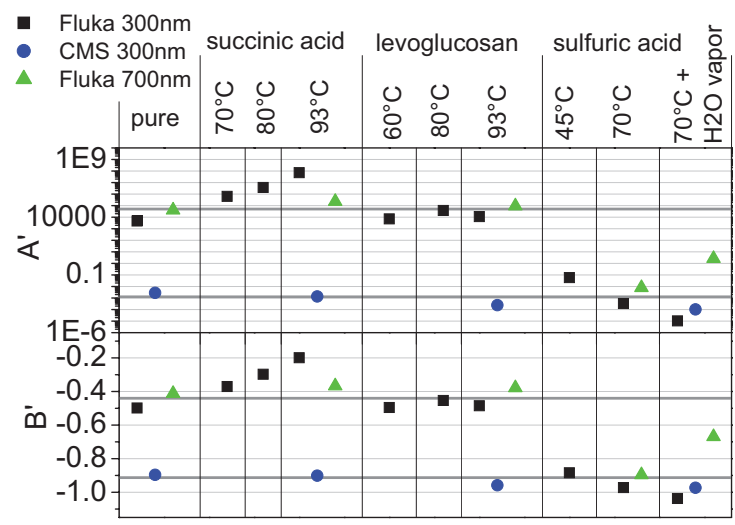

Figure B2. Similar to Fig. 4 in the main text, but values for $A^{\prime}$ and $B^{\prime}$ were obtained by fitting $n_{\mathrm{S}}$ obtained from measured $f_{\text {ice }}$. A separate fit was done for each of the 19 different particle types, each time accounting for all data available from both LACIS and the CFDC. Similar to the fit done for $j_{\text {het }}$, the following equation was used: $n_{\mathrm{S}}=A^{\prime} \cdot \exp \left(B^{\prime} \cdot T\right)$.

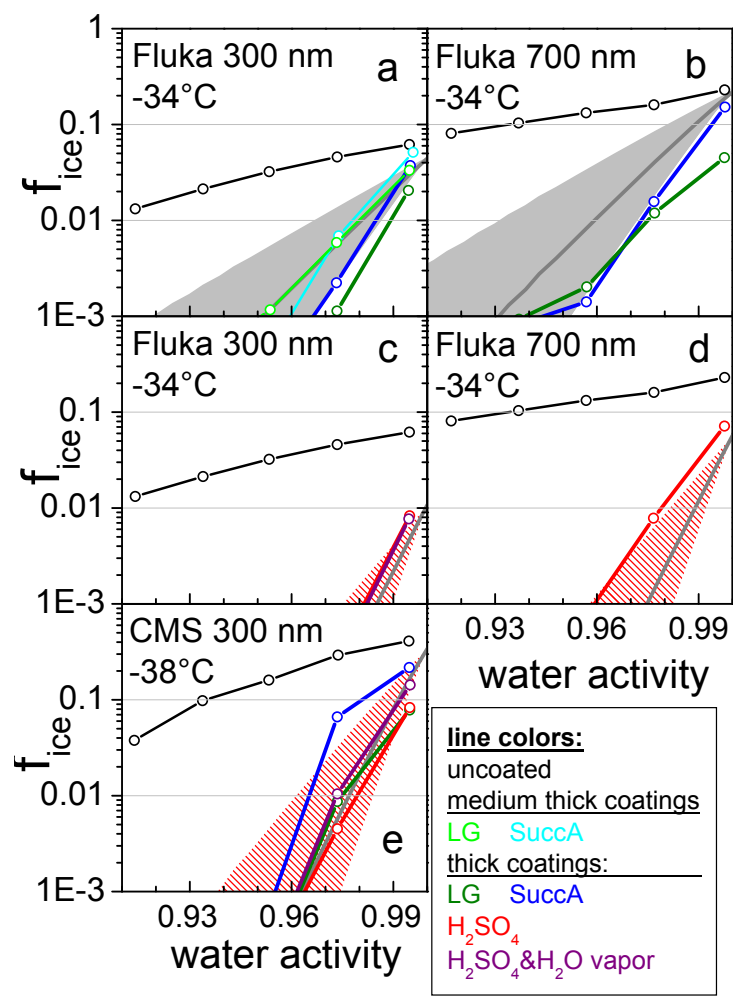

Figure B3. Similar to Fig. 7 in the main text, i.e., showing measured $f_{\text {ice }}$ for deposition ice nucleation and expected ice nucleation behavior for particles which are completely coated by a solution. The difference to Fig. 7 is that the calculations done to obtain the grey and red striped areas were based on average values for $A_{\text {Fluka }}^{\prime}, B_{\text {Fluka }}^{\prime}, A_{\mathrm{CMS}}^{\prime}$ and $B_{\mathrm{CMS}}^{\prime}$ as shown in Fig. B2, i.e., based on $n_{\mathrm{S}}$, and on Eq. (B2).

different from the first set are obtained for all CMS kaolinite particles and Fluka kaolinite particles which were coated with sulfuric acid (with or without water vapor). Grey lines in Fig. B2 represent average values for $A^{\prime}$ and $B^{\prime}$ for these two groups $\left(A_{\text {Fluka }}^{\prime}=5.07 \times 10^{4} \mathrm{~m}^{-2}, B_{\text {Fluka }}^{\prime}=-0.44^{\circ} \mathrm{C}^{-1}\right.$, $A_{\mathrm{CMS}}^{\prime}=0.00127 \mathrm{~m}^{-2}$ and $B_{\mathrm{CMS}}^{\prime}=-0.91^{\circ} \mathrm{C}^{-1}$ ).

These average values of $A^{\prime}$ and $B^{\prime}$ obtained for the two groups were used to estimate the freezing that should be ob- served for subsaturated conditions, with an equation based on Eq. (B1) together with a freezing point depression:

$f_{\text {ice }}\left(a_{\mathrm{w}}\right)=1-\exp \left(-A^{\prime} \cdot \exp \left(B^{\prime} \cdot\left(T+\Delta T_{\text {het }}\left(a_{\mathrm{w}}\right)\right)\right) \cdot s\right)$.

Figure B3 shows the respective results, comparable to what was obtained when the data analysis was based on $j_{\text {het }}$ (see Fig. 7). Measured values (symbols) again agree with the calculated ones (see grey and red striped areas) within 
measurement uncertainty. Hence, results are similar to those described in the main body of the text; i.e., the ice nucleation observed at subsaturated conditions for particles immersed in a concentrated solution droplet can be described using a parameterization of the observed immersion freezing when regarding the freezing point depression caused by the solution.

Overall, the same results and conclusions are obtained, based on our measured data, no matter if the data evaluation is based on a stochastic approach $\left(j_{\text {het }}\right)$ or a deterministic one $\left(n_{\mathrm{S}}\right)$.

\section{Appendix C}

In the present study, we described the ice nucleation induced by kaolinite particles in concentrated solution droplets by using parameterizations obtained from immersion freezing measurements, together with a temperature shift that depended on the melting point depression, and thus water activity of the solution. Two different parameterizations were tested, including either a stochastic or a deterministic treatment of the ice nucleation process. Comparable methods have been applied by a number of previous investigators, as summarized by Koop and Zobrist (2009). Koop and Zobrist (2009) and studies referenced therein also compared and contrasted this approach to one directly relating the immersion freezing nucleation rate to the water- activity of solution droplets in dependence on the type of ice nucleus.

Knopf and Alpert (2013) have now comprehensively examined to what extent it is possible to model immersion freezing based on $a_{\mathrm{w}}$, based on a stochastic treatment. Figure C1 reproduces a part of Fig. 4a from Knopf and Alpert (2013) and shows nucleation rate coefficients $j_{\text {het }}$ as a function of $\Delta a_{\mathrm{W}}$, where $\Delta a_{\mathrm{W}}$ is the observed shift in $a_{\mathrm{w}}$ between the melting curve and the measurement. Figure C1 shows data for CMS kaolinite particles measured by Murray et al. (2011) and Pinti et al. (2012) and an additional linear fit through the data, as given in Knopf and Alpert (2013). Additionally included are CFDC data measured in our study for coated particles at water-subsaturated conditions, separately for coated $300 \mathrm{~nm}$ CMS and Fluka kaolinite particles in the left and right panel of Fig. C1.

Data for coated CMS kaolinite particles are close to or even overlay the data both from Murray et al. (2011) and Pinti et al. (2012). This also applies for data for Fluka kaolinite particles when they are coated with $\mathrm{H}_{2} \mathrm{SO}_{4}$ (with and without water vapor). Data for Fluka kaolinite particles coated with either SuccA or LG show somewhat larger values for the nucleation rate coefficient $j_{\text {het }}$ with a tendency to form a group of their own. This corroborates the results obtained in our study: a parameterization describing coated CMS kaolinite also represents Fluka kaolinite particles well when they have been chemically altered due to a coating with $\mathrm{H}_{2} \mathrm{SO}_{4}$. On the other hand, Fluka kaolinite particles

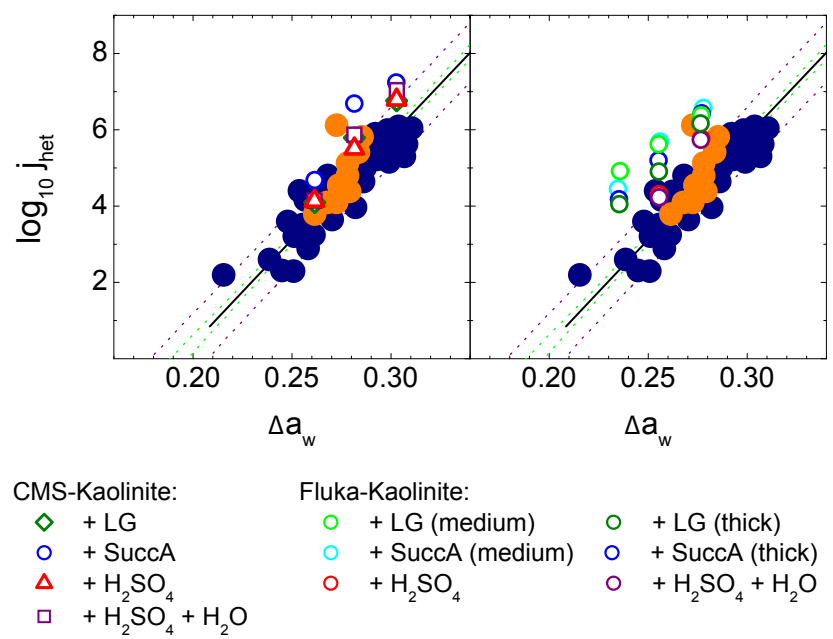

Figure C1. This figure reproduces a part of Fig. 4a from Knopf and Alpert (2013), showing data from Murray et al. (2011) (filled blue dots) and Pinti et al. (2012) (filled orange dots). The solid black line is a linear fit through the data, the dashed green and purple lines represent confidence intervals and prediction bands, respectively, at a $95 \%$ level, as calculated by Knopf and Alpert (2013). The figure additionally includes the data measured in our study for coated particles with the CFDC for water-subsaturated conditions. The left and right panel include data for $300 \mathrm{~nm}$ CMS and Fluka kaolinite, respectively. The figure is discussed in the text in Appendix C.

coated with either SuccA or LG are better described by a separate parameterization, due to their larger ice nucleation ability. A need for different parameterizations for different particle types can also be inferred from Fig. 4 of Knopf and Alpert (2013), where different types of IN presented in different panels (kaolinite, aluminum oxide, iron oxide and fungal spores) show a different dependency of $j_{\text {het }}$ on $\Delta a_{\mathrm{w}}$.

This all corroborates what was found earlier by e.g. Koop and Zobrist (2009) and Knopf and Alpert (2013) and again in this study, i.e., that immersion freezing of solution droplets can be modeled when $a_{\mathrm{w}}$ is known, based on a parameterization of $j_{\text {het }}$ (or $n_{\mathrm{s}}$, see Appendix B) for the respective type of IN. 
Acknowledgements. Financial support for this study was obtained from the German Science Foundation within the framework of the Ice Nucleation research UnIT (DFG Research Unit FOR 1525 INUIT, grant WE 4722/1-1). P. J. DeMott and Y. Tobo acknowledge partial support from US NSF grant ATM-0841602 and the EUROCHAMP II program. Y. Tobo also acknowledges the JSPS Postdoctoral Fellowships for Research Abroad.

Edited by: A. Bertram

\section{References}

Ansmann, A., Tesche, M., Seifert, P., Althausen, D., Engelmann, R., Fruntke, J., Wandinger, U., Mattis, I., and Müller, D.: Evolution of the ice phase in tropical altocumulus: samum lidar observations over Cape verde, J. Geophys. Res., 114, D17208, doi:10.1029/2008JD011659, 2009.

Archuleta, C. M., DeMott, P. J., and Kreidenweis, S. M.: Ice nucleation by surrogates for atmospheric mineral dust and mineral dust/sulfate particles at cirrus temperatures, Atmos. Chem. Phys., 5, 2617-2634, doi:10.5194/acp-5-2617-2005, 2005.

Atkinson, J. D., Murray, B. J., Woodhouse, M. T., Whale, T. F., Baustian, K. J., Carslaw, K. S., Dobbie, S., O’Sullivan, D., and Malkin, T. L.: The importance of feldspar for ice nucleation by mineral dust in mixed-phase clouds, Nature, 498, 355-358, 2013.

Augustin, S., Wex, H., Niedermeier, D., Pummer, B., Grothe, H., Hartmann, S., Tomsche, L., Clauss, T., Voigtländer, J., Ignatius, K., and Stratmann, F.: Immersion freezing of birch pollen washing water, Atmos. Chem. Phys., 13, 10989-11003, doi:10.5194/acp-13-10989-2013, 2013.

Blum, A. E.: Feldspars in Weathering, Feldspars and Their Reactions, Springer, the Netherlands, 1994.

Broadley, S. L., Murray, B. J., Herbert, R. J., Atkinson, J. D., Dobbie, S., Malkin, T. L., Condliffe, E., and Neve, L.: Immersion mode heterogeneous ice nucleation by an illite rich powder representative of atmospheric mineral dust, Atmos. Chem. Phys., 12, 287-307, doi:10.5194/acp-12-287-2012, 2012.

Burrows, S. M., Hoose, C., Pöschl, U., and Lawrence, M. G.: Ice nuclei in marine air: biogenic particles or dust?, Atmos. Chem. Phys., 13, 245-267, doi:10.5194/acp-13-245-2013, 2013.

Clauss, T., Kiselev, A., Hartmann, S., Augustin, S., Pfeifer, S., Niedermeier, D., Wex, H., and Stratmann, F.: Application of linear polarized light for the discrimination of frozen and liquid droplets in ice nucleation experiments, Atmos. Meas. Tech., 6, 1041-1052, doi:10.5194/amt-6-1041-2013, 2013.

Cziczo, D. J., Murphy, D. M., Hudson, P. K., and Thomson, D. S.: Single particle measurements of the chemical composition of cirrus ice residue during crystal-face, J. Geophys. Res., 109, D04201, doi:10.1029/2003JD004032, 2004.

Cziczo, D. J., Froyd, K. D., Gallavardin, S. J., Moehler, O., Benz, S., Saathoff, H., and Murphy, D. M.: Deactivation of ice nuclei due to atmospherically relevant surface coatings, Environ. Res. Lett., 4, 044013, doi:10.1088/1748-9326/4/4/044013, 2009.

Cziczo, D. J., Froyd, K. D., Hoose, C., Jensen, E. J., Diao, M., Zondlo, M. A., Smith, J. B., Twohy, C. H., and Murphy, D. M.: Clarifying the dominant sources and mechanisms of cirrus cloud formation, Science, 340, 1320-1324, 2013.

de Boer, G., Morrison, H., Shupe, M. D., and Hildner, R.: Evidence of liquid dependent ice nucleation in high-latitude strat- iform clouds from surface remote sensors, Geophys. Res. Lett., 38, L01803, doi:10.1029/2010GL046016, 2011.

Deer, W. A., Howie, R. A., and Zussman, J.: An introduction to the rock forming minerals, Addison Wesley Longman, Harlow, UK, 2nd Edn., 1992.

DeMott, P. J.: Laboratory studies of cirrus cloud processes, in: Cirrus, edited by: Lynch, D. K., Sassen, K., Starr, D. O. C., and Stephens, G., Oxford University Press, New York, 102-135, 2002.

DeMott, P. J., Sassen, K., Poellot, M. R., Baumgardner, D., Rogers, D. C., Brooks, S. D., Prenni, A. J., and Kreidenweis, S. M.: African dust aerosols as atmospheric ice nuclei, Geophys. Res. Lett., 30, 1732, doi:10.1029/2003GL017410, 2003.

DeMott, P. J., Prenni, A. J., Liu, X., Kreidenweis, S. M., Petters, M. D., Twohy, C. H., Richardson, M. S., Eidhammer, T., and Rogers, D. C.: Predicting global atmospheric ice nuclei distributions and their impact on climate, P. Natl. Acad. Sci. USA, 107, 11217-11222, 2010.

DeMott, P. J., Prenni, A. J., McMeeking, G. R., Sullivan, R. C., Petters, M. D., Tobo, Y., Niemand, M., Möhler, O., Snider, J. R., Wang, Z., and Kreidenweis, S. M.: Integrating laboratory and field data to quantify the immersion freezing ice nucleation activity of mineral dust particles, Atmos. Chem. Phys. Discuss., submitted, 2014.

Eastwood, M. L., Cremel, S., Wheeler, M. Murray, B. J., Girard, E., and Bertram, A. K.: Effects of sulfuric acid and ammonium sulfate coatings on the ice nucleation properties of kaolinite particles, Geophys. Res. Lett., 36, L02811, doi:10.1029/2008GL035997, 2009.

Fukuta, N. and Schaller, R. C.: Ice nucleation by aerosol particles: Theory of condensation-freezing nucleation, J. Atmos. Sci., 39, 648-655, 1982.

Hallett, J. and Mossop, S. C.: Production of secondary ice particles during the riming process, Nature, 249, 26-28, 1974.

Hartmann, S., Niedermeier, D., Voigtländer, J., Clauss, T., Shaw, R. A., Wex, H., Kiselev, A., and Stratmann, F.: Homogeneous and heterogeneous ice nucleation at LACIS: operating principle and theoretical studies, Atmos. Chem. Phys., 11, 1753-1767, doi:10.5194/acp-11-1753-2011, 2011.

Herich, H., Tritscher, T., Wiacek, A., Gysel, M., Weingartner, E., Lohmann, U., Baltensperger, U., and Cziczo, D. J.: Water uptake of clay and desert dust aerosol particles at sub- and supersaturated water vapor conditions, Phys. Chem. Chem. Phys., 11, 7804-7809, 2009.

Hoffmann, N., Duft, D., Kiselev, A., and Leisner, T.: Contact freezing efficiency of mineral dust aerosols studied in an electrodynamic balance: quantitative size and temperature dependence for illite particles, Faraday Discuss., 165, 383-390, doi:10.1039/C3FD00033H, 2013.

Hoose, C. and Möhler, O.: Heterogeneous ice nucleation on atmospheric aerosols: a review of results from laboratory experiments, Atmos. Chem. Phys., 12, 9817-9854, doi:10.5194/acp-12-98172012, 2012.

Kanji, Z. A., Florea, O., and Abbatt, J. P. D.: Ice formation via deposition nucleation on mineral dust and organics: dependence of onset relative humidity on total particulate surface area, Environ. Res. Lett., 3, 025004, doi:10.1088/1748-9326/3/2/025004, 2008. 
Khvorostyanov, V. I. and Curry, J. A.: The theory of ice nucleation by heterogeneous freezing of deliquescent mixed CCN, Part I: Critical radius, energy, and nucleation rate, J. Atmos. Sci., 61, 2676-2691, 2004.

Knopf, A. D. and Alpert, P. A.: A water activity based model of heterogeneous ice nucleation kinetics for freezing of water and aqueous solution droplets, Faraday Discuss., 165, 513-534, doi:10.1039/c3fd00035d, 2013.

Koehler, K. A., Kreidenweis, S. M., DeMott, P. J., Petters, M. D., Prenni, A. J., and Carrico, C. M.: Hygroscopicity and cloud droplet activation of mineral dust aerosol, Geophys. Res. Lett., 36, L08805, doi:10.1029/2009GL037348, 2009.

Koop, T. and Zobrist, B.: Parameterizations for ice nucleation in biological and atmospheric systems, Phys. Chem. Chem. Phys., 11, 10839-10850, 2009.

Koop, T., Luo, B., Tsias, A., and Peter, T.: Water activity as the determinant for homogeneous ice nucleation in aqueous solutions, Nature, 406, 611-614, 2000.

Kumar, P., Sokolik, I. N., and Nenes, A.: Measurements of cloud condensation nuclei activity and droplet activation kinetics of fresh unprocessed regional dust samples and minerals, Atmos. Chem. Phys., 11, 3527-3541, doi:10.5194/acp-11-3527-2011, 2011.

Ladino Moreno, L. A., Stetzer, O., and Lohmann, U.: Contact freezing: a review of experimental studies, Atmos. Chem. Phys., 13, 9745-9769, doi:10.5194/acp-13-9745-2013, 2013.

Lüönd, F., Stetzer, O., Welti, A., and Lohmann, U.: Experimental study on the ice nucleation ability of size-selected kaolinite particles in the immersion mode, J. Geophys. Res., 115, D14201, doi:10.1029/2009JD012959, 2010.

MacKenzie, A. P., Derbyshire, W., and Reid, D. S.: Non-equilibrium freezing behavior of aqueous systems, Philos. T. Roy. Soc. B, 278, 167-189, 1977.

Marcolli, C.: Deposition nucleation viewed as homogeneous or immersion freezing in pores and cavities, Atmos. Chem. Phys., 14, 2071-2104, doi:10.5194/acp-14-2071-2014, 2014.

Marcolli, C., Luo, B., and Peter, T.: Mixing of the organic fraction: liquids as the thermodynamic stable phases, J. Phys. Chem. A, 108, 2216-2224, 2004.

Mikhailov, E., Vlasenko, S., Martin, S. T., Koop, T., and Pöschl, U.: Amorphous and crystalline aerosol particles interacting with water vapor: conceptual framework and experimental evidence for restructuring, phase transitions and kinetic limitations, Atmos. Chem. Phys., 9, 9491-9522, doi:10.5194/acp-9-9491-2009, 2009.

Murray, B. J., Broadley, S. L., Wilson, T. W., Atkinson, J. D., and Wills, R. H.: Heterogeneous freezing of water droplets containing kaolinite particles, Atmos. Chem. Phys., 11, 4191-4207, doi:10.5194/acp-11-4191-2011, 2011.

Murray, B. J., O’Sullivan, D., Atkinson, J. D., and Webb, M. E.: Ice nucleation by particles immersed in supercooled cloud droplets, Chem. Soc. Rev., 41, 6519-6554, 2012.

Niedermeier, D., Hartmann, S., Shaw, R. A., Covert, D., Mentel, T. F., Schneider, J., Poulain, L., Reitz, P., Spindler, C., Clauss, T., Kiselev, A., Hallbauer, E., Wex, H., Mildenberger, K., and Stratmann, F.: Heterogeneous freezing of droplets with immersed mineral dust particles - measurements and parameterization, Atmos. Chem. Phys., 10, 3601-3614, doi:10.5194/acp-10-36012010, 2010.
Niedermeier, D., Hartmann, S., Clauss, T., Wex, H., Kiselev, A., Sullivan, R. C., DeMott, P. J., Petters, M. D., Reitz, P., Schneider, J., Mikhailov, E., Sierau, B., Stetzer, O., Reimann, B., Bundke, U., Shaw, R. A., Buchholz, A., Mentel, T. F., and Stratmann, F.: Experimental study of the role of physicochemical surface processing on the IN ability of mineral dust particles, Atmos. Chem. Phys., 11, 11131-11144, doi:10.5194/acp-11-11131-2011, 2011.

Parsons, M. T., Mak, J., Lipetz, S. R., and Bertram, A. K.: Deliquescence of malonic, succinic, glutaric, and adipic acid particles, J. Geophys. Res., 109, D06212, doi:10.1029/2003JD004075, 2004.

Petters, M. D. and Kreidenweis, S. M.: A single parameter representation of hygroscopic growth and cloud condensation nucleus activity, Atmos. Chem. Phys., 7, 1961-1971, doi:10.5194/acp-71961-2007, 2007.

Pinti, V., Marcolli, C., Zobrist, B., Hoyle, C. R., and Peter, T.: Ice nucleation efficiency of clay minerals in the immersion mode, Atmos. Chem. Phys., 12, 5859-5878, doi:10.5194/acp-12-58592012, 2012.

Pruppacher, H. R. and Klett, J. D.: Microphysics of Clouds and Precipitation, Kluwer Academic Publishers, Dordrecht, the Netherlands, 1997.

Rasmussen, D. H.: Thermodynamics and nucleation phenomena a set of experimental-observations, J. Cryst. Growth, 56, 56-66, 1982.

Reitz, P., Spindler, C., Mentel, T. F., Poulain, L., Wex, H., Mildenberger, K., Niedermeier, D., Hartmann, S., Clauss, T., Stratmann, F., Sullivan, R. C., DeMott, P. J., Petters, M. D., Sierau, B., and Schneider, J.: Surface modification of mineral dust particles by sulphuric acid processing: implications for ice nucleation abilities, Atmos. Chem. Phys., 11, 7839-7858, doi:10.5194/acp-117839-2011, 2011.

Rogers, D. C.: Development of a continuous flow thermal gradient diffusion chamber for ice nucleation studies, Atmos. Res., 22, 149-181, 1988.

Rogers, D. C., DeMott, P. J., Kreidenweis, S. M., and Chen, Y.: A continous-flow diffusion chamber for airborne measurements of ice nuclei, J. Atmos. Ocean. Tech., 18, 725-741, 2001.

Sassen, K. and Dodd, G. C.: Homogeneous nucleation rate for highly supercooled cirrus cloud droplets, J. Atmos. Sci., 45, 1357-1369, 1988.

Sassen, K., DeMott, P. J., Prospero, J. M., and Poellot, M. R.: Saharan dust storms and indirect aerosol effects on clouds: crystal-face results, Geophys. Res. Lett., 30, 1633, doi:10.1029/2003GL017371, 2003.

Simoneit, B. R. T., Schauer, J. J., Nolte, C. G., Oros, D. R., Elias, V. O., Fraser, M. P., Rogge, W. F., and Cass, G. R.: Levoglucosan, a tracer for cellulose in biomass burning and atmospheric particles, Atmos. Environ., 33, 173-182, 1999.

Spichtinger, P. and Cziczo, D. J.: Impact of heterogenous ice nuclei on homogenous freezing events in cirrus clouds, J. Geophys. Res., 115, D14208, doi:10.1029/2009JD012168, 2010.

Sullivan, R. C., Minambres, L., DeMott, P. J., Prenni, A. J., Carrico, C. M., Levin, E. J. T., and Kreidenweis, S. M.: Chemical processing does not always impair heterogeneous ice nucleation of mineral dust particles, Geophys. Res. Lett., 37, L24805, doi:10.1029/2010GL045540, 2010a.

Sullivan, R. C., Petters, M. D., DeMott, P. J., Kreidenweis, S. M., Wex, H., Niedermeier, D., Hartmann, S., Clauss, T., Stratmann, F., Reitz, P., Schneider, J., and Sierau, B.: Irreversible loss of 
ice nucleation active sites in mineral dust particles caused by sulphuric acid condensation, Atmos. Chem. Phys., 10, 1147111487, doi:10.5194/acp-10-11471-2010, 2010b.

Tobo, Y., DeMott, P. J., Raddatz, M., Niedermeier, D., Hartmann, S., Kreidenweis, S. M., Stratmann, F., and Wex, H.: Impacts of chemical reactivity on ice nucleation of kaolinite particles: a case study of levoglucosan and sulfuric acid, Geophys. Res. Lett., 39, L19803, doi:10.1029/2012GL053007, 2012.

Vali, G.: Nucleation terminology, J. Atmos. Sci., 16, 575-576, 1985. Vonnegut, B.: The nucleation of ice formation by silver iodide, J. Appl. Phys., 18, 593-595, 1947.

Welti, A., Lüönd, F., Stetzer, O., and Lohmann, U.: Influence of particle size on the ice nucleating ability of mineral dusts, Atmos. Chem. Phys., 9, 6705-6715, doi:10.5194/acp-9-6705-2009, 2009.

Wex, H., Ziese, M., Kiselev, A., Henning, S., and Stratmann, F.: Deliquescence and hygroscopic growth of succinic acid particles measured with LACIS, Geophys. Res. Lett., 34, L17810, doi:10.1029/2007GL030185, 2007.
Wheeler, M. J. and Bertram, A. K.: Deposition nucleation on mineral dust particles: a case against classical nucleation theory with the assumption of a single contact angle, Atmos. Chem. Phys., 12, 1189-1201, doi:10.5194/acp-12-1189-2012, 2012.

Wiacek, A., Peter, T., and Lohmann, U.: The potential influence of Asian and African mineral dust on ice, mixed-phase and liquid water clouds, Atmos. Chem. Phys., 10, 8649-8667, doi:10.5194/acp-10-8649-2010, 2010.

Zimmermann, F., Weinbruch, S., Schütz, L., Hofmann, H., Ebert, M., Kandler, K., and Worringen, A.: Ice nucleation properties of the most abundant mineral dust phases, J. Geophys. Res., 113, D23204, doi:10.1029/2008JD010655, 2008.

Zolles, T.: Heterogeneous ice nucleation on mineral dust particles, M.Sc. thesis, Faculty of Technical Chemistry, Vienna University of Technology, 2013.

Zuberi, B., Bertram, A. K., Cassa, C. A., Molina, L. T., and Molina, M. J.: Heterogeneous nucleation of ice in $\left(\mathrm{NH}_{4}\right)_{2} \mathrm{SO}_{4}-$ $\mathrm{H}_{2} \mathrm{O}$ particles with mineral dust immersions, Geophys. Res. Lett., 29, 1504, doi:10.1029/2001GL014289, 2002. 